NBSIR 84-2832

\title{
Economizer Algorithms for Energy Management and Control Systems
}

U.S. DEPARTMENT OF COMMERCE National Bureau of Standards Center for Building Technology

Building Equipment Division

Washington, DC 20234

February 1984

Sponsored by:

Office of Building and Community Systems

U.S. Department of Energy

$-Q C$

1.S. Navy Civil Engineering Laboratory

100

I.S. Department of Defense

.456

$34-2332$ 

ECONOMIZER ALGORITHMS FOR ENERGY MANAGEMENT AND CONTROL SYSTEMS

Cheol Park

George E. Kelly

James Y. Kao

U.S. DEPARTMENT OF COMMERCE

National Bureau of Standards

Center for Building Technology

Building Equipment Division

Washington, DC 20234

February 1984

Sponsored by:

Office of Building and Community Systems

U.S. Department of Energy

U.S. Navy Civil Engineering Laboratory

U.S. Department of Defense

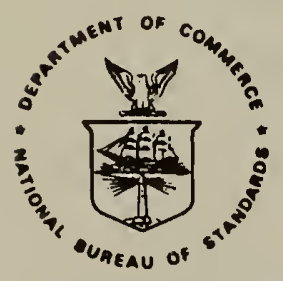

U.S. DEPARTMENT OF COMMERCE, Malcolm Baldrige, Secretary NATIONAL BUREAU OF STANDARDS, Ernest Ambler, Director 



\section{ABSTRACT}

Economizer cycles have been recognized as important energy conservation measures for building air handling systems and have been included in most Energy Management and Control Systems (EMCS). This report describes the psychrometric processes of the most commonly used economizer cycles and presents algorithms for implementing these cycles on a typical Energy Management and Control System.

Economizer cycles included in this study are dry-bulb and enthalpy types, as applied to both dry coils and sprayed coils. In addition, an enhancement to the normal enthalpy economizer cycle algorithm is presented for dual-duct or multi-zone system which takes into account differences in the costs of heating energy and cooling energy. Computer program listings of the algorithms and sample input/output data are shown in the appendices. A brief discussion of common types of air handling systems is also given to help the reader better understand the application of the algorithms presented in this report.

Key words: control strategies; cooling energy; dry-bulb economizer cycle; energy management and control system; enthalpy economizer cycle; heating energy. 


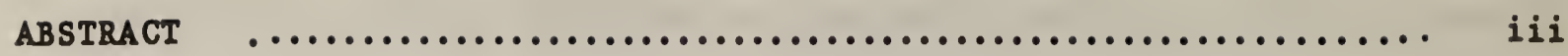

LIST OF PIGURES $\ldots \ldots \ldots \ldots \ldots \ldots \ldots \ldots \ldots \ldots \ldots \ldots \ldots \ldots \ldots \ldots \ldots \ldots \ldots \ldots \ldots$

1. INTRODUCTION $\ldots \ldots \ldots \ldots \ldots \ldots \ldots \ldots \ldots \ldots \ldots \ldots \ldots \ldots \ldots \ldots \ldots \ldots \ldots \ldots$

2. COMMON TYPES OF HVAC SYSTEMS $\ldots \ldots \ldots \ldots \ldots \ldots \ldots \ldots \ldots \ldots \ldots \ldots \ldots \ldots$

3. THE DRY-BULB ECONOMIZER CYCLE ...................... 11

4. DRY-BULB ECONOMIZER ALGORITHM ...................... 22

5. ENTHALPY ECONOMIZER CYCLE $\ldots \ldots \ldots \ldots \ldots \ldots \ldots \ldots \ldots \ldots \ldots \ldots \ldots \ldots$

6. ENTHALPY ECONOMIZER ALGORITHM ...................... 33

7. DUAL-DUCT SYSTEMS $\ldots \ldots \ldots \ldots \ldots \ldots \ldots \ldots \ldots \ldots \ldots \ldots \ldots \ldots \ldots \ldots \ldots \ldots$

8. ALGORITHM ENHANCEMENT FOR DUAL-DUCT AND MDLTI-ZONE SYSTEMS $\ldots \ldots .41$

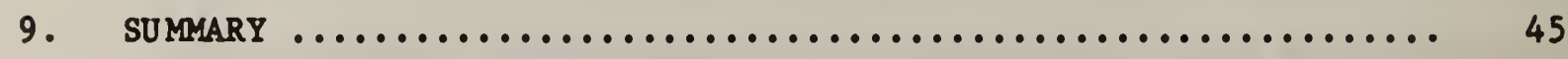

REFERENCES $\ldots \ldots \ldots \ldots \ldots \ldots \ldots \ldots \ldots \ldots \ldots \ldots \ldots \ldots \ldots \ldots \ldots \ldots \ldots \ldots \ldots \ldots \ldots$

APPENDIX A. COMPUTER PROGRAM LISTING OF THE DRY-BULB ECONOMIZER

ALGORITHM (DBE), AND SAMPLE INPUT AND OUTPUT ........ A-1

APPENDIX B. COMPUTER PROGRAM LISTING OF THE ENTHALPY ECONOMIZER

ALGORITH $($ ETC1), AND SAMPLE INPUT AND OUTPUT ....... B-1

APPENDIX C. DERIVATION OF THE DIMENSIONLESS FACTOR, $\lambda \ldots \ldots \ldots \ldots \ldots \ldots$.

APPENDIX D. COMPUTER PROGRAM LISTING OF THE ENTHALPY ECONOMIZER ALGORITHM WITH ENHANCEMENT (ETC2), AND SAMPLE INPUT AND

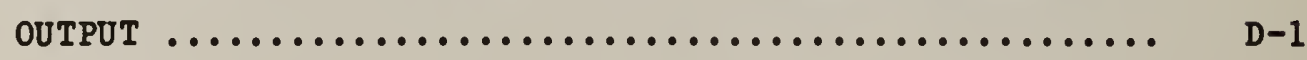




\section{LIST OF FIGURES}

Figure 2. Single-zone air handling unit with reheat system $\ldots . . . .6$

Figure 3. Single-zone air handling unit with sprayed coil ....... 7

Figure 4. Variable air volume (VAV) system ................... 8

Figure 5. Dual duct syster $\ldots \ldots \ldots \ldots \ldots \ldots \ldots \ldots \ldots \ldots \ldots \ldots \ldots \ldots \ldots \ldots . \ldots \ldots$

Figure 6. Psychrometric chart of dry-bulb economizer cycle for systems not using sprayed coils or air washers ......... 12

Figure 7. Operation of a dry-bulb economizer cycle on a single-zone

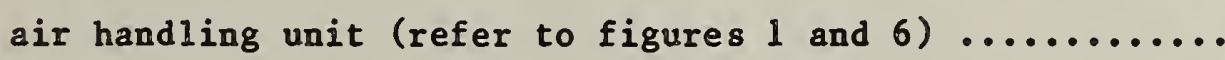

Figure 8. Operation of a dry-bulb economizer cycle on a single-zone reheat system (refer to figures 2 and 6) $\ldots . \ldots \ldots \ldots \ldots$

Figure 9. Psychrometric chart of dry-bulb economizer cycle for systems employing sprayed coils or air washers ..........

Figure 10. Operation of a dry-bulb economizer cycle on an air handling system with sprayed coils or air washers

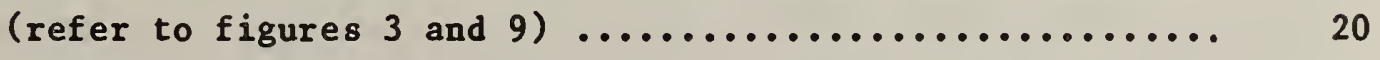

Figure 11. Logic flow diagram of dry-bulb economizer cycle ........ 26

Figure 12. Fsychrometric chart of enthalpy economizer cycle for systems which do not employ sprayed cooling coils or air washers $\ldots \ldots \ldots \ldots \ldots \ldots \ldots \ldots \ldots \ldots \ldots \ldots \ldots \ldots \ldots \ldots$

Figure 13. Psychrometric chart of enthalpy economizer cycle for systems with sprayed cooling coils or air washers .......

Figure 14. Logic flow diagram of the enthalpy economizer cycle .... 
Pigure 15. Psychrometric charts of the dual-duct system without

sprayed coil or air washer $\ldots \ldots \ldots \ldots \ldots \ldots \ldots \ldots \ldots \ldots$

Figure 16. Logic flow diagram of the enhancement routine for

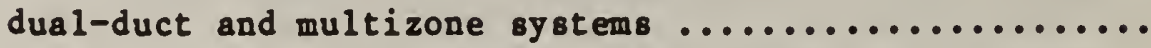




\section{INTRODUCTION}

Rising energy costs, accompanied by decreasing prices for computers and microprocessors, have resulted in a rapid increase in the use of Energy Management and Control Systems (EMCS) in new and existing buildings. With the proper application algorithms, these EMCS are capable of implementing building control strategies which minimize the use of heating and air conditioning equipment to save appreciable amounts of energy. One such control strategy which is commonly found on today's EMCS is the use of outdoor air for cooling a building's interior when outdoor temperature and humidity conditions permit. Such a strategy is usually referred to as an economizer cycle.*

There are two basic types of economizer cycles. A dry-bulb economizer, which is the simpler of the two, utilizes the outdoor and return air dry-bulb temperatures to position the outdoor, return, and relief air dampers. An enthalpy economizer performs the same functions using the enthalpies of the outdoor and return air. The latter has been shown to save more energy $[1,2,3]$, but requires the installation of additional sensors to measure the relative humidities or dew point temperatures of the outdoor and return air. These sensors require frequent maintenance and calibration to prevent measurement errors which can lead to a significant increase in building energy consumption [4] through the improper use of outdoor air for cooling.

*The phrase "economizer cycle" is misleading since there is really no thermodynamic "cycle" involved. However, this terminology has been commonly used in the literature in the past and it is adopted in this paper to avoid additional confusion. 
This report describes both the dry-bulb and enthalpy economizer cycles and presents algorithms for implementing them on a typical Energy Management and Control system. In addition, an enhancement to the enthalpy economizer is presented for dual-duct systems which takes into account the relative costs of heating and cooling the air supplied to the conditioned space.

Computer programs, written in Fortran 77, are presented in the appendices for the two economizer algorithms, and for the enhancement covering dual-duct systems, with calling routines that can be used to check the operation of the economizer programs. Sample input data and resulting output are also included. It should be pointed out, however, that these programs do not contain software for reading sensors, actuating the outdoor, return, and relief air damper motors, or positioning these dampers 80 as to obtain the desired mixed air temperature, since these functions are typically system dependent.

In addition, since there are many different kinds of systems and many ways of controlling each type, it is always important to thoroughly analyze an application before implementing a new control strategy. The algorithms presented in the report, while covering most typical HVAC installations, may require some modifications before being used in the actual operation of a specific building system. 


\section{COMMON TYPES OF HVAC SYSTEMS}

The numerous types of HVAC systems used in buildings and the various methods employed for controlling their operation have been discussed extensively elsewhere $[5,6,7]$. While it is beyond the scope of this report to try and review this information, it is useful to briefly discuss some of the more common systems found in commercial buildings in the United States. This will serve as background material for better understanding the algorithm presented in the following sections.

Figure 1 shows a typical single-zone air handling unit found in many small buildings [6]. This system is controlled to provide either heating or cooling, but not both at the same time. During cooling, there is no direct control of the humidity level in the conditioned space, although some indirect control can be achieved by properly selecting the cooling coil to provide the desired ratio of sensible to total cooling capacity at full load.

Two techniques are commonly employed for implementing dry-bulb economizer control on the above system [1]. The first utilizes an outside, return, and relief air damper controller to regulate the mixed air temperature to a given set point. The second sequences the dampers and cooling coil flow rate control valve so that the cooling coil discharge controller regulates the damper position before the cooling coil valve opens. Although the former is easier to implement with pneumatic controls, the latter is slightly more 


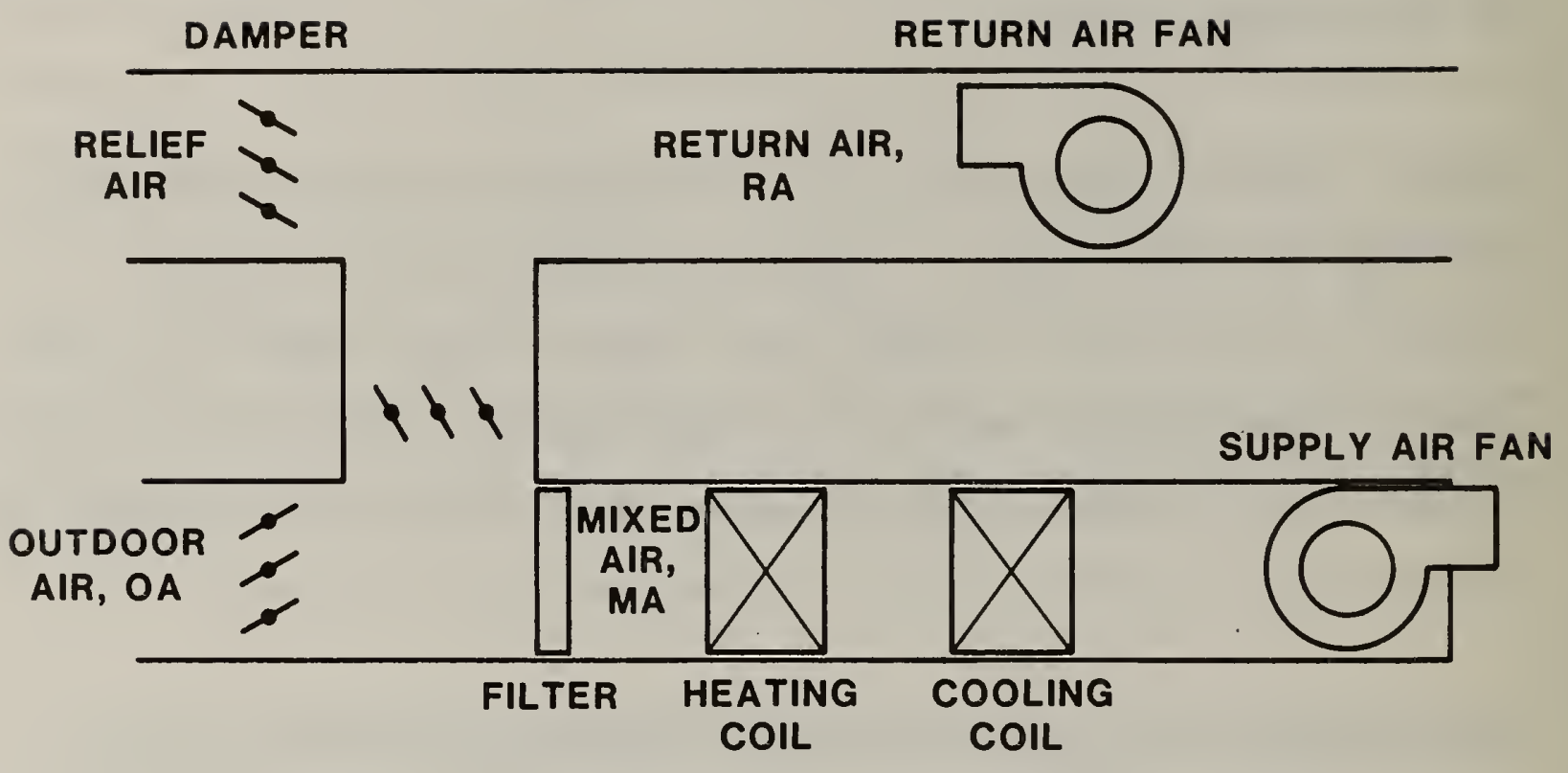

Figure 1. Single-zone air handling unit 
general in that it assures that there is no conflict between control of the cooling coil valve and control of the dampers. In addition, it is capable of providing proper control for both dry coil and sprayed coil systems. Because of these features, the second control technique (i.e., the one utilizing the cooling coil discharge temperature) was selected as the basis of the economizer algorithms presented in this report.

In order to limit the maximum relative humidity in a conditioned space [6], a HVAC system designer will often interchange the relative position of the cooling and heating coils in the system discussed above. This results in the single-zone reheat system shown in figure 2. If more than one zone is involved, the single heating coil can be replaced by reheat coils or induction reheat units in each zone.

If tighter humidity control in the conditioned space is desired, a designer will often use a sprayed cooling coil or even an air washer in place of a cooling coil [6]. The former system is shown in figure 3. Again, the single reheat coil in these figures can be replaced by multiple reheat coils or induction reheat units in each of the different zones.

Another system that is enjoying immense popularity these days because of high energy costs is the Variable Air Volume (VAV) system shown in figure $4[6,8]$. The rate of air flow may be controlled by a fan inlet (vortex) damper, a fan discharge damper, mechanical or electrical fan speed control, variable volume boxes in each zone, or some combination of these. 


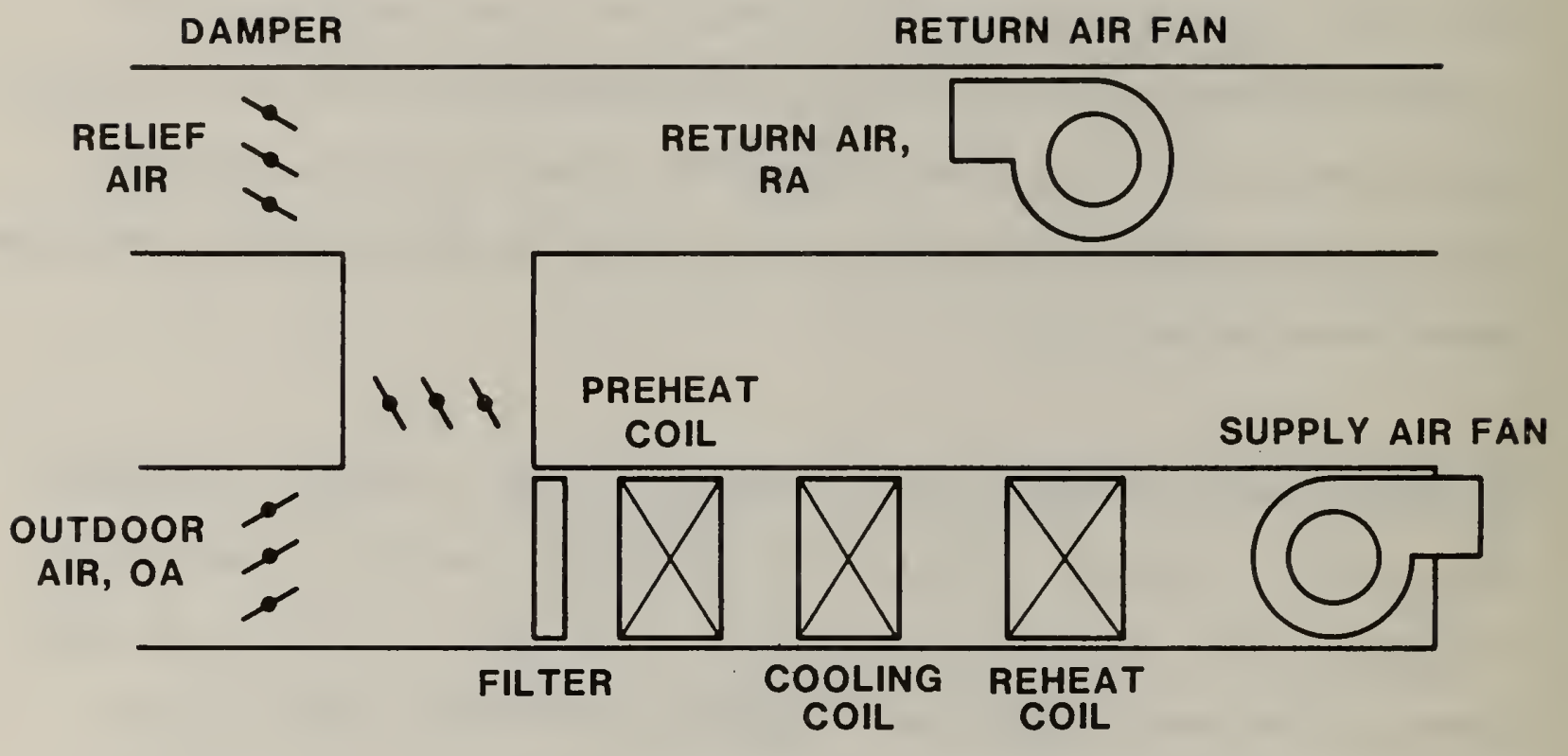

Figure 2. Single-zone air handling unit with reheat system 


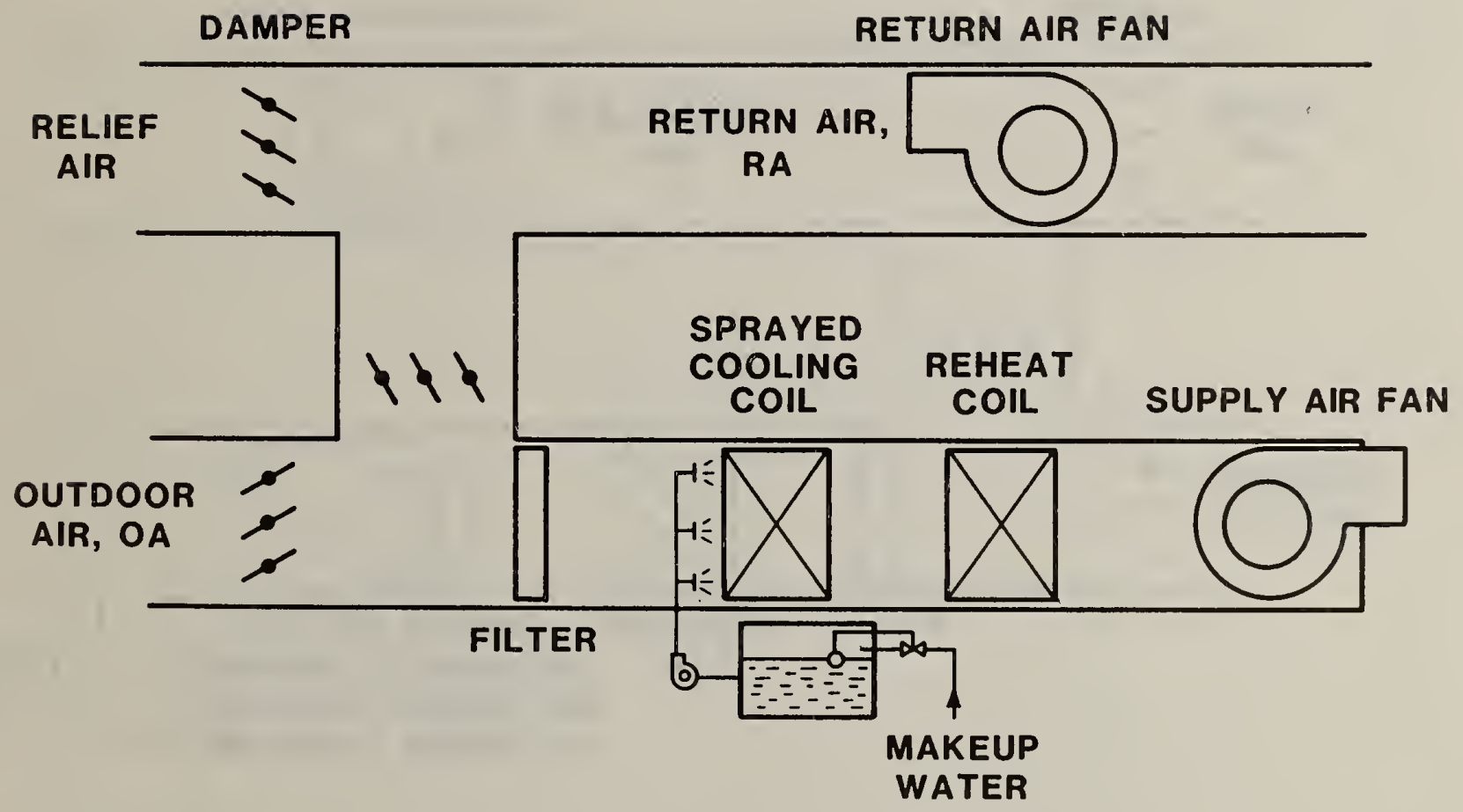

Figure 3. Single-zone air handling unit with sprayed coil 


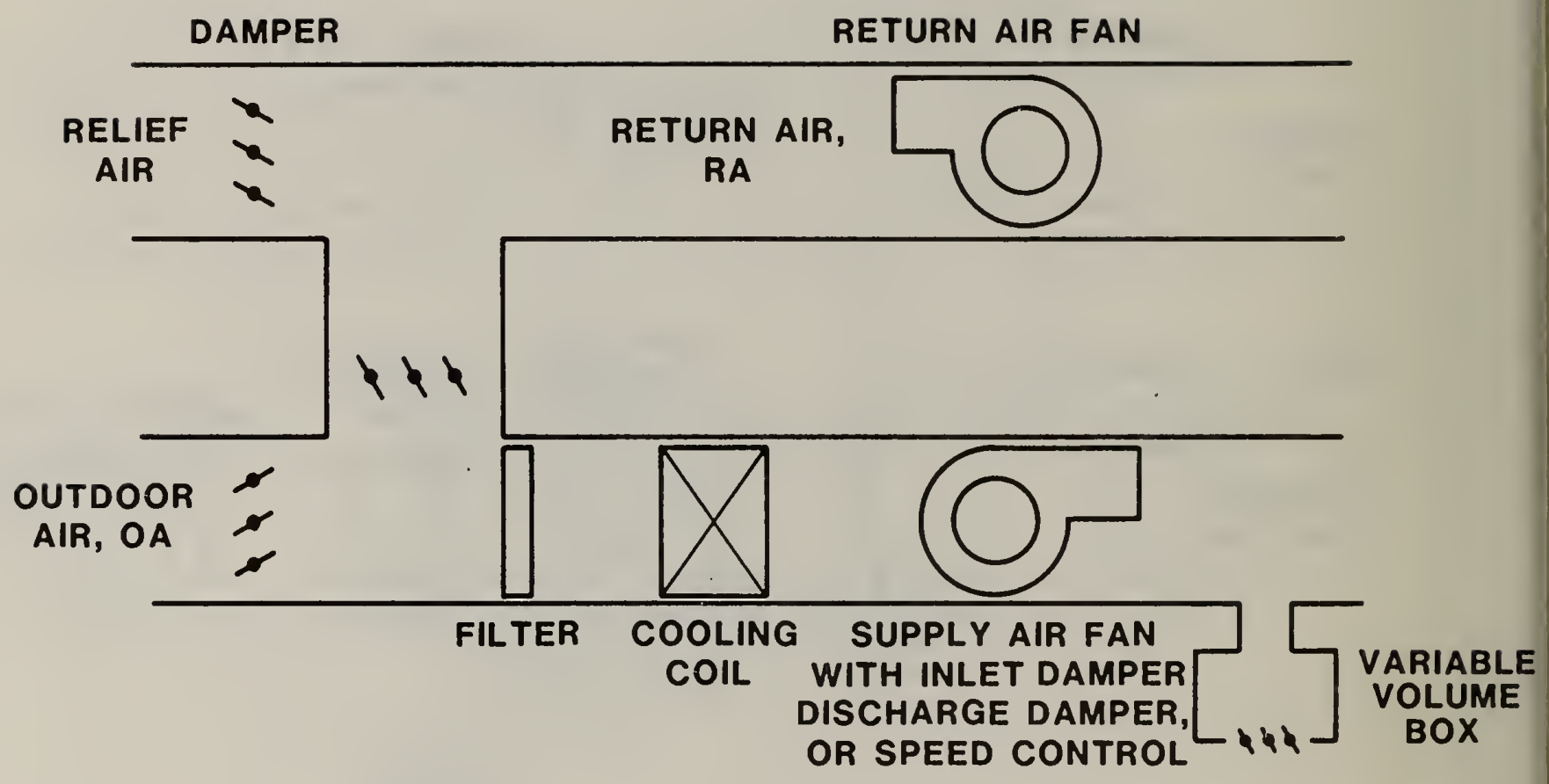

Figure 4. Variable air volume (VAV) system 
Applications involving multiple zones are also handled using dual-duct and multi-zone systems to provide conditioned air to the occupied spaces in a building [6]. Both of these systems mix chilled and heated air to obtain the desired supply air conditions. The only difference is that the dual-duct system, shown in figure 5, mixes the cold and hot air at each zone, while the multi-zone system mixes it at the air handling unit and then ducts the mixed air to the zone. 


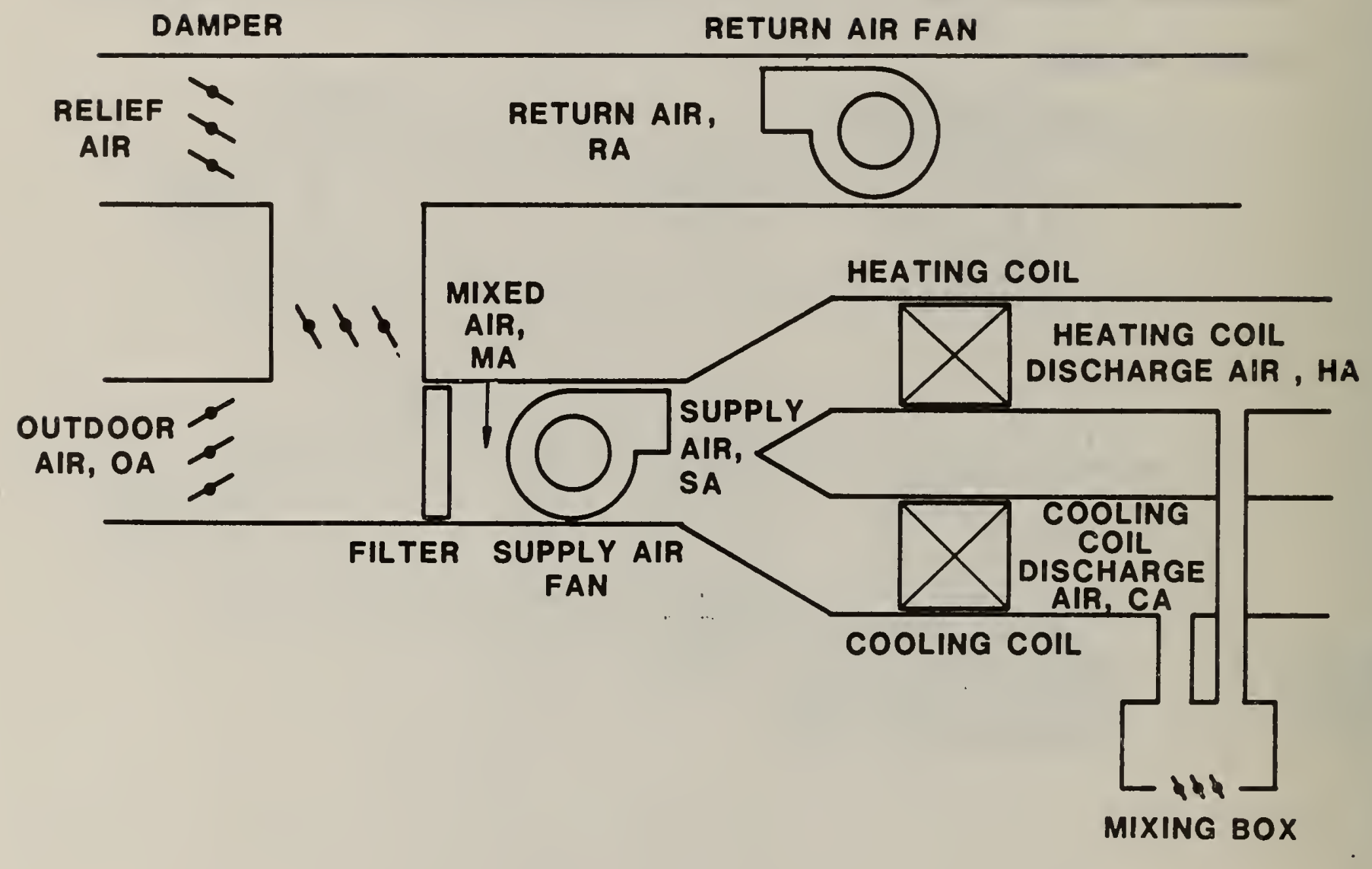

Figure 5. Dual-duct system 
Dry bulb economizer cycles employing outdoor air for "free cooling" have become a common feature on air handling systems. For systems not using sprayed cooling coils or air washers, the basic dry bulb economizer cycle can be described using the sketch of the single air handling unit in figure 1 and the psychrometric chart shown in figure 6 .

When the outdoor air temperature is above a changeover temperature, $\mathrm{T}_{\mathrm{CO}}$, and in region Ib in figure 6 , it is always desirable to minimize the amount of outdoor air used because the enthalpy of the outside air will be greater than the enthalpy of the return air. In region Ia, the enthalpy of the outside aix is less than the enthalpy of the return air, and, under certain conditions, there could be some advantage in using the maximum amount of outdoor air. However, to utilize outdoor conditions in this entire region requires measurement of the thermodynamic states of the outdoor air and return air. These measurements are, however, not available since if they were, an enthalpy eonomizer cycle would be used. For this reason, the outdoor and relief air dampers should be at their minimum open position and the return air damper (see figure 1) at its maximum open position whenever the outdoor air is in either Region Ia or Ib. These damper positions should also be set to satisfy the minimum fresh air requirements of the zone served by the air handling unit. 
I: Min. $O A+$ mechanical cooling

II: Max. OA + mechanical cooling

III: Mixed $O A$ and RA

IV: Min. $O A+$ heating

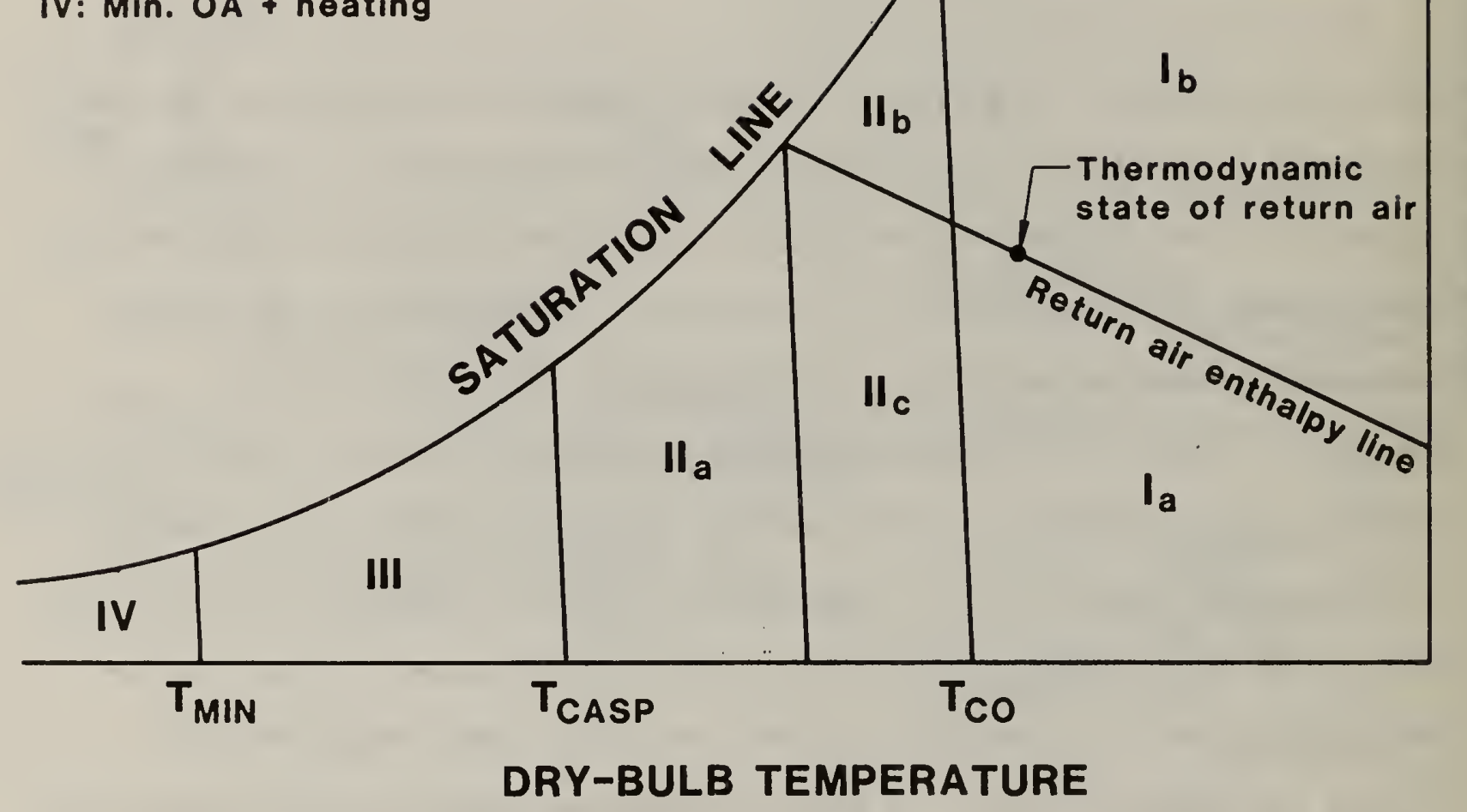

Figure 6. Psychrometric chart of dry-bulb economizer cycle for systems not using sprayed colls or air washers 


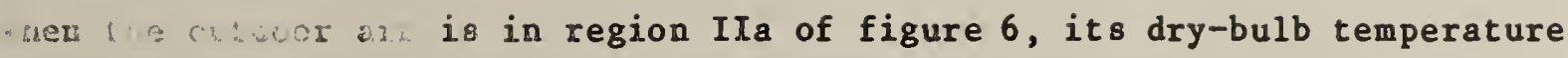
is greater than (or equal to) the dry-bulb set point temperature of the cooling coil discharge air, $\mathrm{T}_{\mathrm{CASP}}$, but less than the changeover temperature, $\mathrm{T}_{\mathrm{CO}}$. In this region, the maximum amount of outdoor air should be used, along with mechanical cooling to reduce the temperature of the mixed air to $\mathrm{T}_{\mathrm{CASP}}$. The changeover temperature, $\mathrm{T}_{\mathrm{CO}}$, should be selected so as to maximize the sum of the positive savings from region IIc and the negative savings (loss) from region IIb over the entire year. The latter is due to the high humidity conditions that exist when the outdoor air conditions are in this region (i.e., IIb). The value of $\mathrm{T}_{\mathrm{CO}}$ varies with the climate and the typical conditions assumed for the thermodynamics state of the return air. Typical values of $\mathrm{T}_{\mathrm{CO}}$ are given in reference [8] for most of the major U.S. cities.

For outdoor air dry-bulb temperatures below $\mathrm{T}_{\text {CASP, }}$ the cooling coil valve should be closed and the outdoor, return and relief air dampers modulated to maintain a cooling coil discharge temperature equal to $\mathrm{T}_{\text {CASP }}$. Under these conditions, the outdoor and relief air dampers will be at their maximum open position when the outdoor air dry-bulb temperature is near $\mathrm{T}_{\mathrm{CASP}}$ and gradually close, until they reach their minimum open positions, as the outdoor temperature continues to decrease. The return air damper operates in the opposite direction - gradually opening as the outdoor temperature falls below $\mathrm{T}_{\text {CASP }}$

For systems with preheat coils, such as the-one in figure 2, the outdoor and relief air dampers go from whatever position they are in to a minimum open 
position when the outdoor dry-bulb temperature drops to some minimum value, $\mathrm{T}_{M I N}$. In region $I V$, with outdoor temperature below $T_{M I N}$, only the minimum amount of outside air, needed to satisfy the building's fresh air requirements, is used and the preheat coils are operated to raise the mixed air temperature to $\mathrm{T}_{\text {CASP. }}$. The value of $\mathrm{T}_{\text {MIN }}$ may be selected to correspond to that outdoor temperature which results in a mixed air temperature of $\mathrm{T}_{\text {CASP }}$ when the minimum amount of outside air is mixed with return air. However, this may not protect the preheat coils from freezing and, depending on the system employed, it may be necessary to select a higher value for $\mathrm{T}_{\text {MIN }}$.

All of the systems shown in figures 1 through 5 are usually controlled in. the manner described above when a dry-bulb economizer cycle is employed. However, there are some interesting differences in the actual operation of the systems that are worth discussing. For the single-zone air handling unit in figure 1, the outdoor and return air are mixed to obtain a temperature $\mathrm{T}_{\text {CASP }}$ leaving the cooling coil (with no mechanical refrigeration) when the outdoor temperature is in region III of figure 6. Maximum and minimum outdoor air, plus mechanical refrigeration, is used to maintain this same cooling coil discharge temperature when the outdoor temperature is in region II and I, respectively. Operation in these three regions is shown in figure 7 . The value of $\mathrm{T}_{\text {CASP }}$ is selected to satisfy the space conditioning needs of the zone served. For the reheat system in figure 2, ${ }$ CAsp is usually lower than the supply air temperature needed to cool the conditioned space. This is done to remove moisture from the air and thus limit the maximum relative humidity 


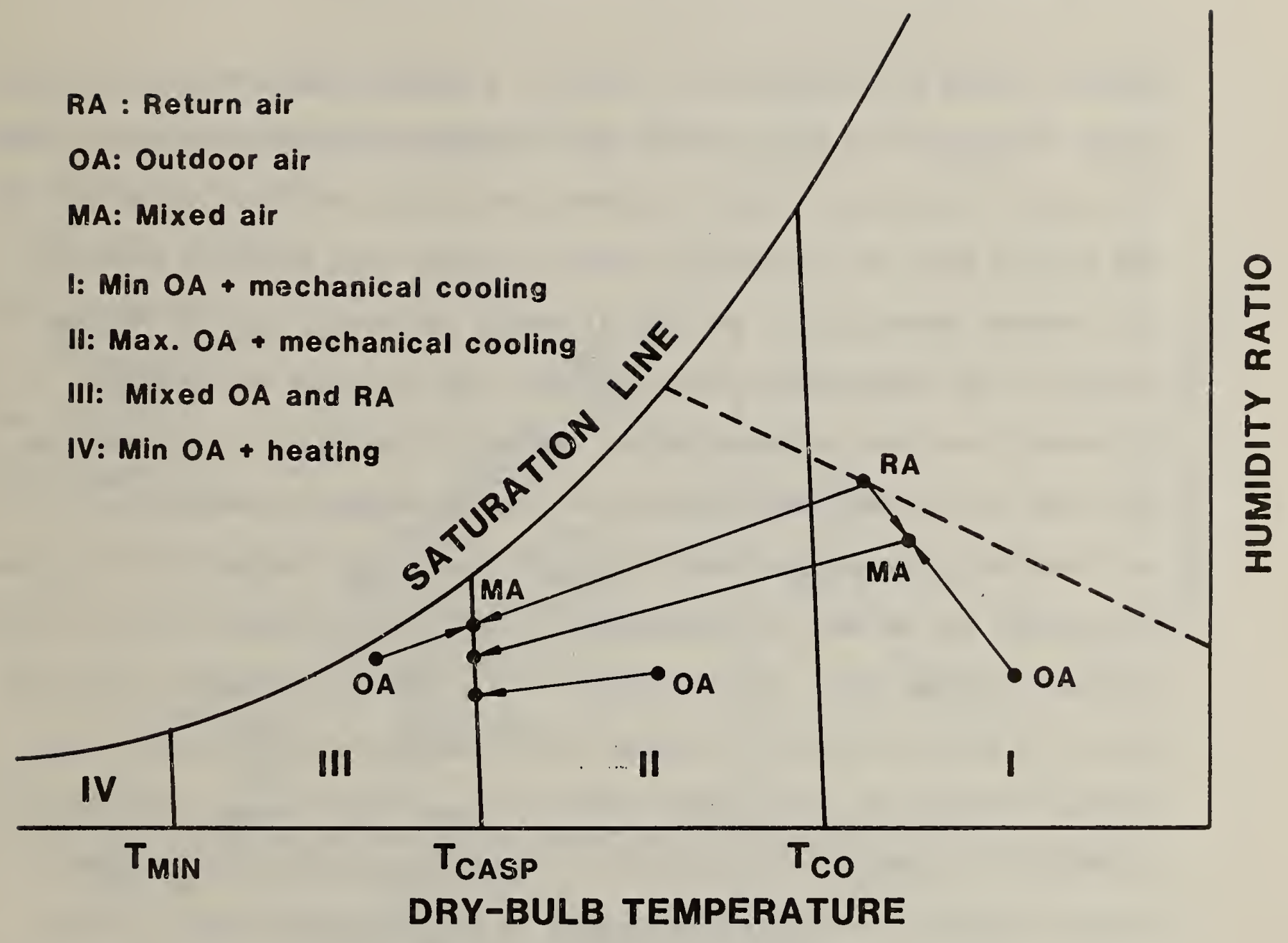

Figure 7. Operation of a dry-bulb economizer cycle on a single-zone air handling unit (refer to figures $I$ and 6 ) 
allowed in the space and/or to satisfy a diversity of cooling loads among a number of zones. As a result, the air leaving the cooling coil must be reheated, either using a single reheat coil as illustrated in figure 8 , or using separate coils in each of the different zones.

Figure 9 shows the psychrometric chart for a system using a sprayed coil (as shown in figure 3) or an air washer. The dry-bulb temperature measured leaving the coil or air washer is actually very close to the dew point temperature of the leaving air. Air entering the spray or washer will be cooled down along its constant enthalpy line until it is nearly saturated. Thus the various regions on the psychrometric chart for this type of system are somewhat different than those discussed above. Region III in figure 9 is bounded on the right by the constant enthalpy line passing through the saturation curve at a dew point temperature equal to $\mathrm{I}_{\text {CASP }}$. Outdoor air in region III is mixed with return air so that the thermodynamic state of the mixed air falls on this constant enthalpy line. Actual control of the system is unchanged, since the mixing is done to maintain a cooling coil discharge air temperature (or air washer discharge air temperature) equal to $\mathrm{T}_{\mathrm{CASP}}$. Since $\mathrm{T}_{\mathrm{CASP}}$ is usually lower than the temperature required to satisfy the sensible cooling load in order to maintain close humidity control in the conditioned space, this air will typically be reheated to the desired supply air temperature. The minimum amount of outside air is used in regions $I$ a and $I b$ for the same reasons discussed above for systems not employing sprayed coils or air washers. The changeover temperature, ${ }^{T}{ }_{C O}$, is, however, likely to shift somewhat due to changes in the shape of regions II and III and because the energy requirements 
I: Min OA + mechanical cooling

II: Max. OA + mechanical cooling

III: Mixed $O A$ and $R A$

IV: Min $O A+$ heating

RA: Return air

OA: Outside air

MA: Mixed air

SA: Supply air

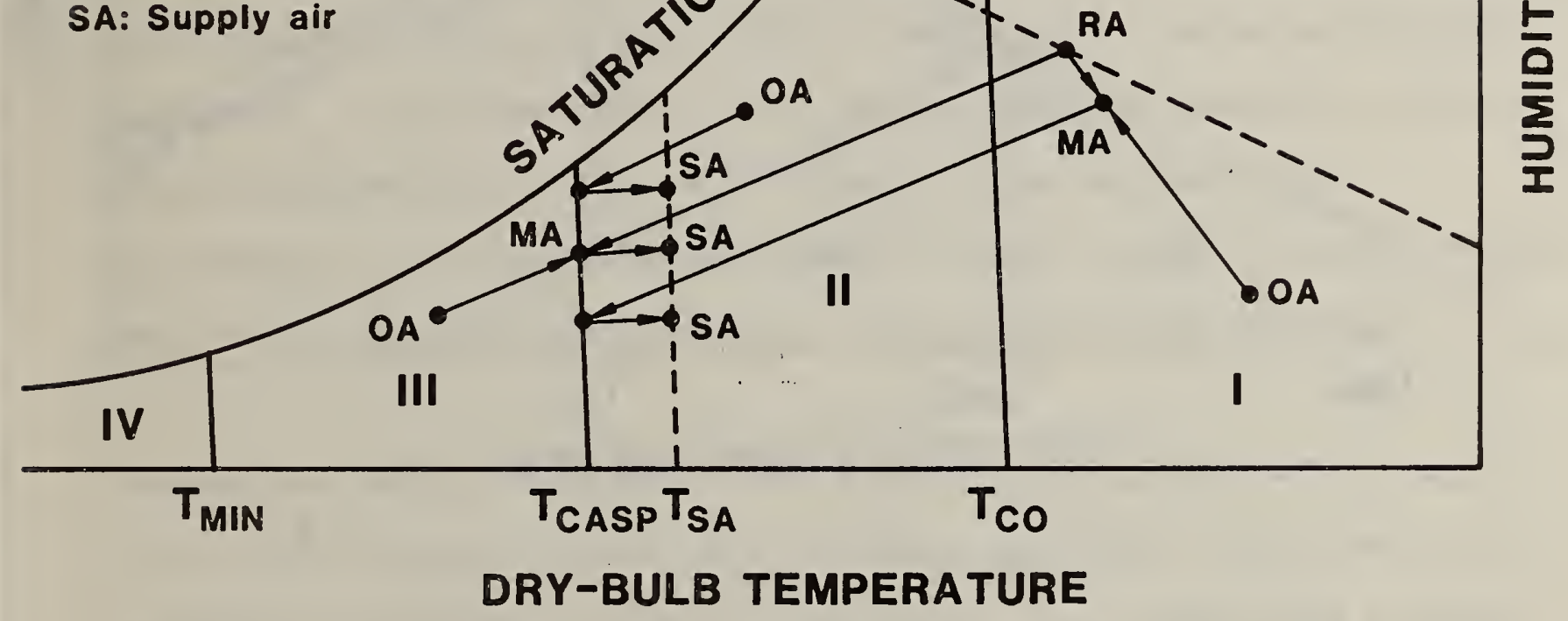

Figure 8. Operation of a dry-bulb economizer cycle on a single-zone reheat system (refer to figures 2 and 6 ) 
I: Min OA + mechanical cooling

II: Max. OA + mechanical cooling

III: Mixed $O A$ and RA

IV: Min $O A+$ heating

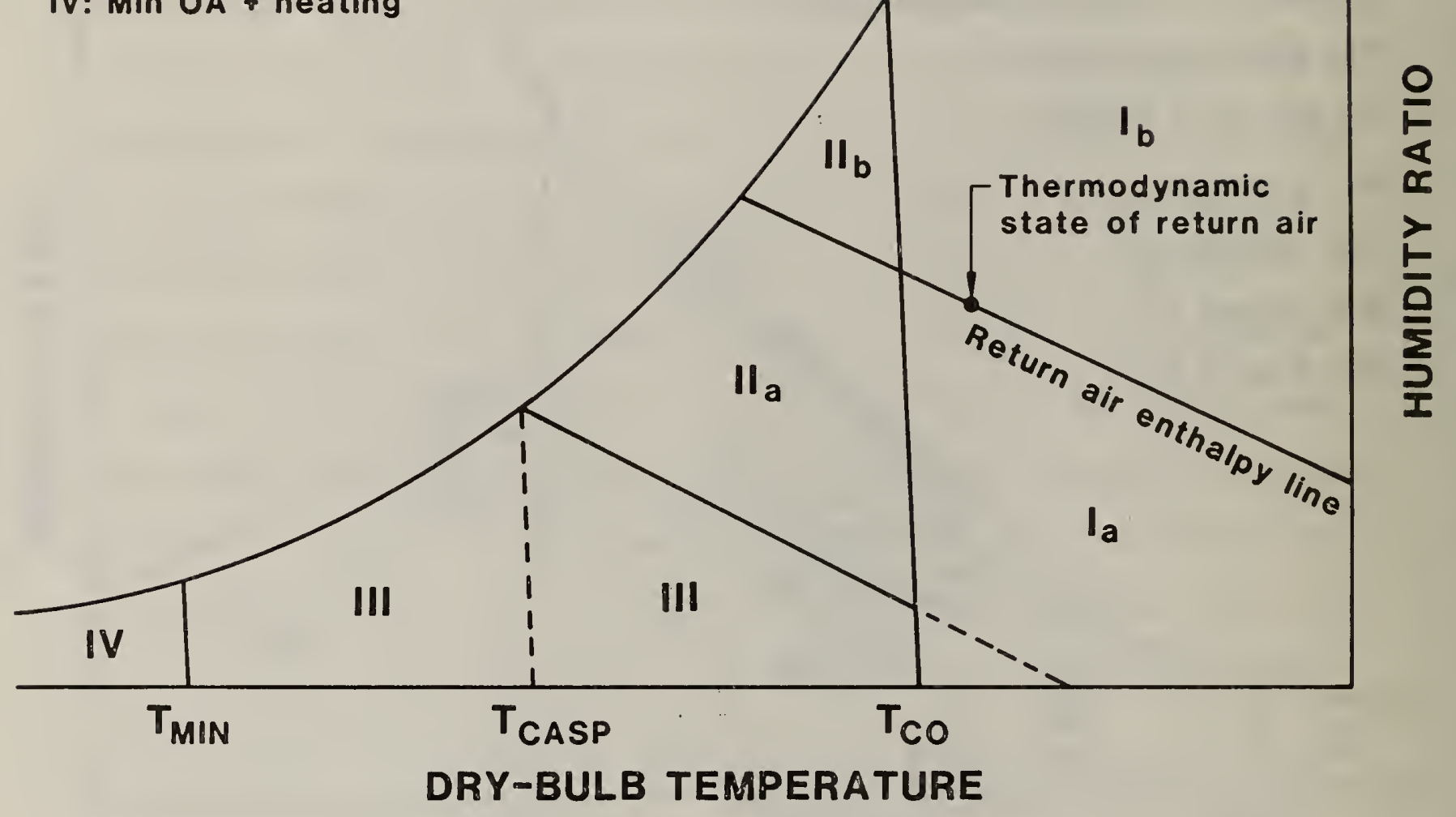

Figure 9. Psychrometric chart of dry-bulb economizer cycle for systems employing sprayed coils or air washers 
to condition the supply air in these regions is different for systems employing sprzyed coils or air washers. Since this changeover temperature

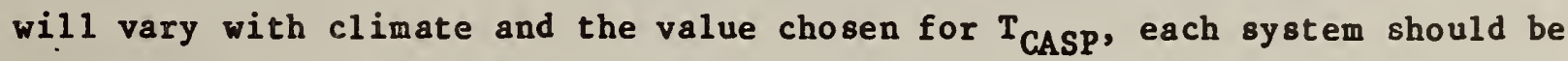
analyzed separately to determine the optimal value of $\mathrm{T}_{\mathrm{CO}}$. Operation of a dry-bulb economizer cycle in regions I, II, and III for systems employing sprayed coils or air washers is shown in figure 10.

The variable air volume system, shown in figure 4, behaves like either the single zone air handling unit in figure 1 or the reheat system in figure 2 , depending on whether a heating coil (not shown in figure 4) is placed upstream or downstream of the cooling coil. The difference is that the variable volume system provides multi-zone control with a single supply duct by varying the quantity of air supplied to each zone. The psychrometric charts for a drybulb economizer cycle applied to this type of system are identical, respectively, to the ones discussed above in figures 6 and 9 for VAV systems which do not employ spray coils or air washers and for those that do.

As mentioned earlier, dual duct systems and multi-zone systems differ only in the location where hot air and cold air mixing takes place. These systems may use either non-sprayed or sprayed cooling coils. In a system using a sprayed cooling coil (or an air washer), all of the air is usually passed through the sprayed coil, and then part is reheated and mixed with the cooling air to satisfy the various zone requirements. However, the most common system configuration uses a non-sprayed cooling coil and such an arrangement (for a 
I: Min. $O A$ + mechanlcal coollng

II: Max. OA + mechanical coollng

iii: Mlxed $O A$ and $R A$

IV: Min. $O A$ + heatlng

RA: Return air

OA: Outside air

MA: Mixed air

SA: Supply air

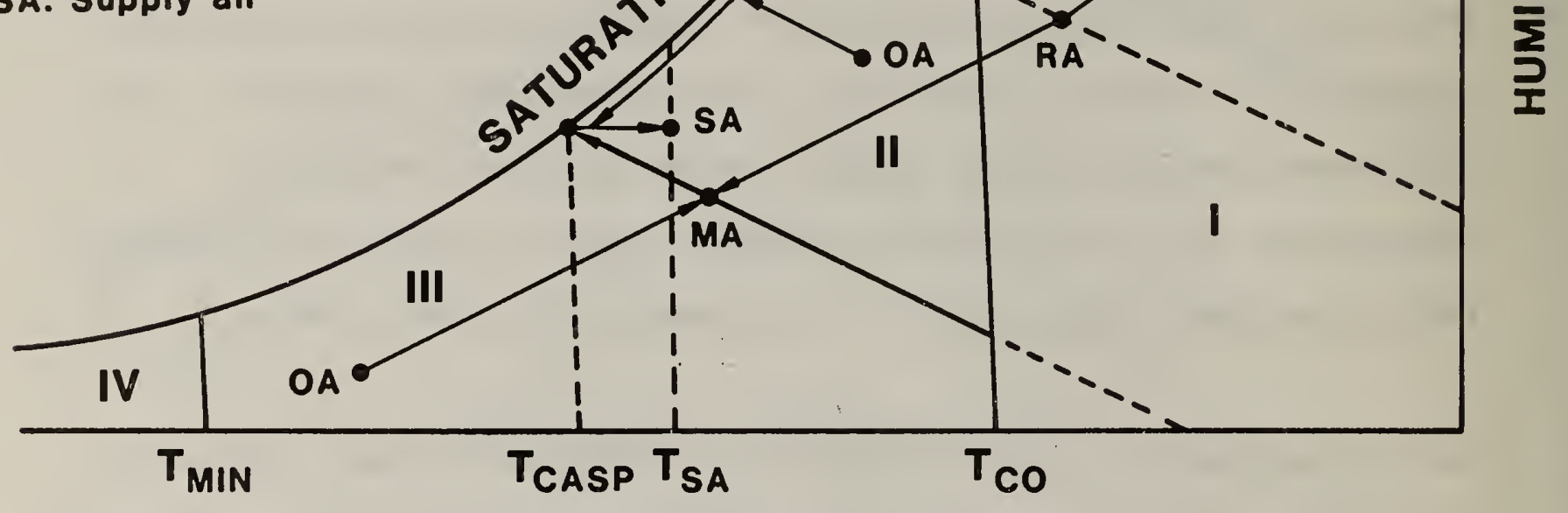

DRY-BULB TEMPERATURE

Figure 10. Operation of a dry-bulb economizer cycle on an air handling system with sprayed coils or air washers

(refer to figures 3 and 9) 
dual-duct system) was shown in figure 5. The psychrometric charts for the typical application of dry-bulb economizer cycles to these systems are given in figures 6 and 9 for systems with non-sprayed and sprayed coils, respectively. 
4. DRY-BULB ECONOMIZER ALGORITHMS

Although the presentation in the previous section on how a dry-bulb economizer cycle works tends to be somewhat complex because of the different types of coils and systems involved, the actual dry-buib economizer algorithm is very simple. In addition, it is usually implemented on the various BVAC systems described above in almost an identical manner. The algorithm may be expressed in words as follows:

(a) If the measured outdoor air temperature, $\mathrm{T}_{\mathrm{OA}}$, is greater than or equal to the preselected changeover temperature, $\mathrm{T}_{\mathrm{CO}}$, then the outdoor, return and relief air dampers should be positioned to admit the minimum amount of outside air to the building that is necessary to satisfy the fresh air requirement 8 .

(b) For HVAC systems not using sprayed coils (or air washers), the dampers should be positioned to admit the maximum amount of outdoor air when the outdoor temperature, $T_{O A}$, is greater than or equal to $T_{C A S P}$ but less than the changeover temperature, $\mathrm{T}_{\mathrm{CO}}$. For systems employing sprayed cooling coils (or air washers) the dampers should be positioned to admit the maximum possible outdoor air 88 long as $\mathrm{T}_{O A}$ is below $\mathrm{T}_{\mathrm{CO}}$ and mechanical cooling is required to maintain the cooling coil discharge air temperature, $\mathrm{T}_{\mathrm{CA}}$, at its set point, $\mathrm{T}_{\mathrm{CASP}}$. 
(c) The outdoor, return, and relief air dampers should be positioned to mix outdoor air and return air when $\mathrm{T}_{O A}$ is less than $\mathrm{T}_{\mathrm{CASP}}$ for systems not using sprayed coils (or air washers) or when $\mathrm{T}_{\mathrm{OA}}$ is less than $\mathrm{T}_{\mathrm{CO}}$ and mechanical cooling is not required to maintain $\mathrm{T}_{\mathrm{CA}}$ at $\mathrm{T}_{\mathrm{CASP}}$ for systems with sprayed coils (or air washers). In both cases, the mixing should be controlled so as to maintain the cooling air discharge temperature, $\mathrm{T}_{\mathrm{CA}}$, at its set point, ${ }_{\text {CASP }}$.

(d) For systems with preheating coils, the mixed damper control should be overridden and the dampers positioned to admit the minimum amount of outdoor air when the outdoor air temperature, $T_{O A}$, is equal to or below some assigned value, $\mathrm{T}_{\mathrm{MIN}}$. The minimum amount of outdoor air should be that required to meet the minimum fresh air requirements of the conditioned space.

The actual sequencing of the dampers and the cooling coil valve can be accomplished in a number of ways. If pneumatic actuators are used, the dampers and coil actuators can be assigned different pressure ranges so that it is physically impossible for controlled mixing and cooling coil operation to occur at the same time. For direct digital control systems, the same thing can be accomplished by introducing a small control differential or dead zone, $\Delta$, about the set point temperature of the cooling coil discharge air. This is to prevent excessive switching between control of the cooling coil and control of the dampers when the outside air temperature is very close to $T_{\text {CASP. This }}$ approach is implemented by checking to see if $\mathrm{T}_{\mathrm{CA}}$ is greater than or equal to 
$\mathrm{T}_{\mathrm{CASP}}+\Delta$ before switching from mixing control of the dampers to control of the cooling coil. Likewise, $\mathrm{T}_{\mathrm{CA}}$ must be lese than or equal to $\mathrm{T}_{\mathrm{CASP}}-\Delta$, before switching from cooling coil valve control to control of the dampers for mixing purposes.

When the outside air temperature, $\mathrm{T}_{O A}$ is at or close to the changeover temperature, $\mathrm{T}_{\mathrm{CO}}$, the use of control differential, $\Delta$, can minimize the frequency of switching between the outdoor air damper position to admit the maximum amount of outside air (Region II) and that to admit the minimum amount of outdoor air (Region I). This floating region associated with $\Delta$ is bounded by $\mathrm{T}_{\mathrm{CO}} \pm \Delta$.

Actual control of the outdoor, return, and relief air dampers when operating in the mixing mode and control of the cooling coil valve will depend upon the type of control system used. A dedicated pneumatic or electronic controller could be employed or direct digital control can be provided by the energy management and control system. It will be pointed out, however, that direct digital control of valves and dampers can be accomplished either using position algorithms which require feedback on the position of a valve or a damper, or using velocity algorithms which do not require feedback.

A logic flow diagram representing the operation of the dry-bulb economizer algorithm is shown in figure 11. The input veriables to this algorithm are: 


A
${ }^{\mathrm{T}} \mathrm{CO}$
profram)
$\mathrm{T}_{\mathrm{CA}}$ measured cooling coil discharge air dry-bulb temperature
$\mathrm{T}_{\mathrm{CASP}} \quad$ set point value of cooling coil discharge air dry-bulb
temperature
control differential (or dead zone) to minimize the switching
frequency of damper or coil valve opening. For simplicity, a
single control differential is used for all floating regions in
the dry-bulb economizer cycle algorithm in this report.
specified outdoor air dry-bulb temperature where the minimum
position of the outside air damper is reached
logical variable indicating type of cooling coil, SPRAY = TRUE
if system uses a sprayed coil or air washer, FALSE otherwise

The output variables of the algorithm are:

CCLV logical variable indicating whether cooling coil valve is to be

$$
\begin{aligned}
& \text { controlled to maintain } \mathrm{T}_{\mathrm{CA}} \text { equal to } \mathrm{T}_{\mathrm{CASP}} \text { (CCLV }=\mathrm{TRUE} \text { ) or } \\
& \text { closed (CCLV }=\text { FALSE) }
\end{aligned}
$$

DAMPOA integer variable for controlling dampers

$=0$ for admitting minimum outdoor air

$=1$ for controlling damper to mix outdoor and return air to maintain $\mathrm{T}_{\mathrm{CA}_{A}}$ equal to $\mathrm{T}_{\mathrm{CASP}}$

$=2$ for admitting maximum outdoor air 


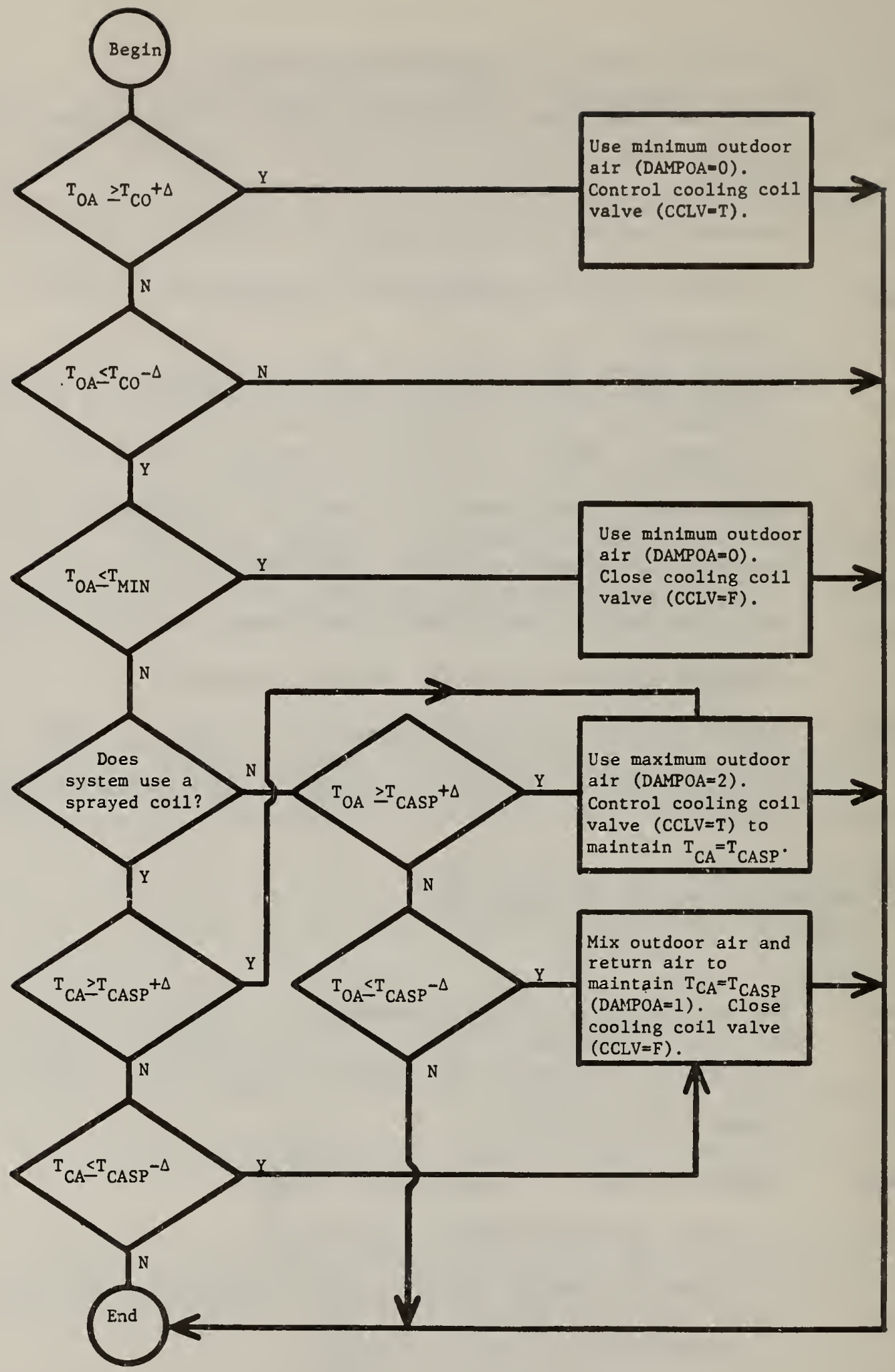

Figure 11. Logic flow diagram of dry-bulb economizer cycle 
The above algorithre assumes that the building return air temperature, $T_{R A}$, is at or close to the set point temperature of the conditioned space. If the HVAC system has recently been started up after the end of an unoccupied period and $T_{R A}$ is not near the desired conditioned space temperature, then this economizer algorithm should not be used or else it should be overridden or supplemented with a building warm-up or cool down control algorithm.

A computer program, DBE, for this dry-bulb algorithm, written in Fortran 77, is contained in Appendix A. A calling routine, DBEMAIN, is also presented there. Sample input and output of the program using a Sperry 1100/82 computer are provided. 


\section{ENTHALPY ECONOMIZER CYCLE}

In an enthalpy economizer cycle, the specific enthalpy or heat content of both the outdoor air and the return air are determined. This information is then used to decide whether the minimum or maximum amount of outside air should be used or if the outside and return air should be mixed to satisfy the sensible and latent cooling requirements of the conditioned space. Since these decisions are made in real time and can dynamically account for any changes in the thermodynamic state of the outside and return air, the enthalpy economizer tends, in general, to save more energy than the dry-bulb economizer cycle $[2,3]$. The need for an assigned changeover temperature, $T_{C O}$, to account for typical outdoor and return air conditions is also eliminated.

The operation of the enthalpy economizer cycle can most easily be explained using psychrometric charts similar to the ones discussed above. Figure 12 is such a chart for a system which does not employ a sprayed cooling coil or an air washer. In region Ia of this figure, the enthalpy of the out side air is greater than that of the return air and thus the dampers should be set to admit the minimum amount of outside air required to meet the fresh air needs of the conditioned space. In region $\mathrm{Ib}$, the enthalpy of the outside air is less than the return air enthalpy, but the amount of sensible cooling necessary to reduce the temperature of the outside air to the set point of the cooling coil discharge air is greater than the amount needed if return air is used. Because of this and because the majority of HVAC systems will be doing 
only sensible cooling when the outside temperature is in most of region Ib, the minimum amount of out side air should be used in this region. In region II, the use of the maximum possible out side air will reduce the system's energy consumption since both the enthalpy and dry-bulb temperature of the outside air are less than the corresponding values for the return air.

When the out side temperature is in region III of figure 12, the outside and return air streams should be mixed to obtain a mixed air temperature of $\mathrm{T}_{\text {CASP }}$ and the cooling coil valve should be closed (i.e., no mechanical cooling is done). For HVAC systems with preheat coils, such as the one in figure 2, the outdoor and relief air dampers should be reset to their minimum open position whenever the outside air temperature falls below an assigned minimum value, $\mathrm{T}_{\text {MIN }}$ (Region IV).

The psychrometric chart for an enthalpy economizer cycle applied to HVAC systems using a sprayed cooling coil or air washer is shown in figure 13. As in the case of the dry-bulb economizer cycle applied to this type of system, region III is larger and extends, on the right side, to the enthalpy line

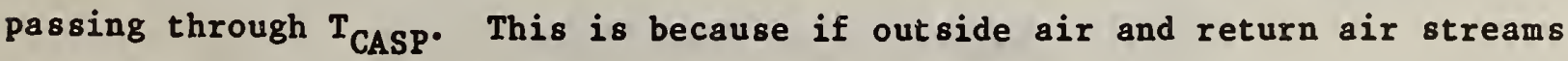
are mixed to obtain this enthalpy, the resulting mixed air will be cooled down to approximately $\mathrm{T}_{\mathrm{CASP}}$ by means of evaporative cooling as it passes through the sprayer or air washer without mechanical cooling being done. The region corresponding to maximum outside air use, region II, is also extended, on the right, to the enthalpy line of the return air. Thus, for systems employing sprayed coils or air washers, it is desirable to use the maximum amount of 
I: MIn. OA + mechanical cooling

II: Max. OA + mechanical coollng

III: Mixed $O A$ and $R A$

IV: Min. $O A+$ heating

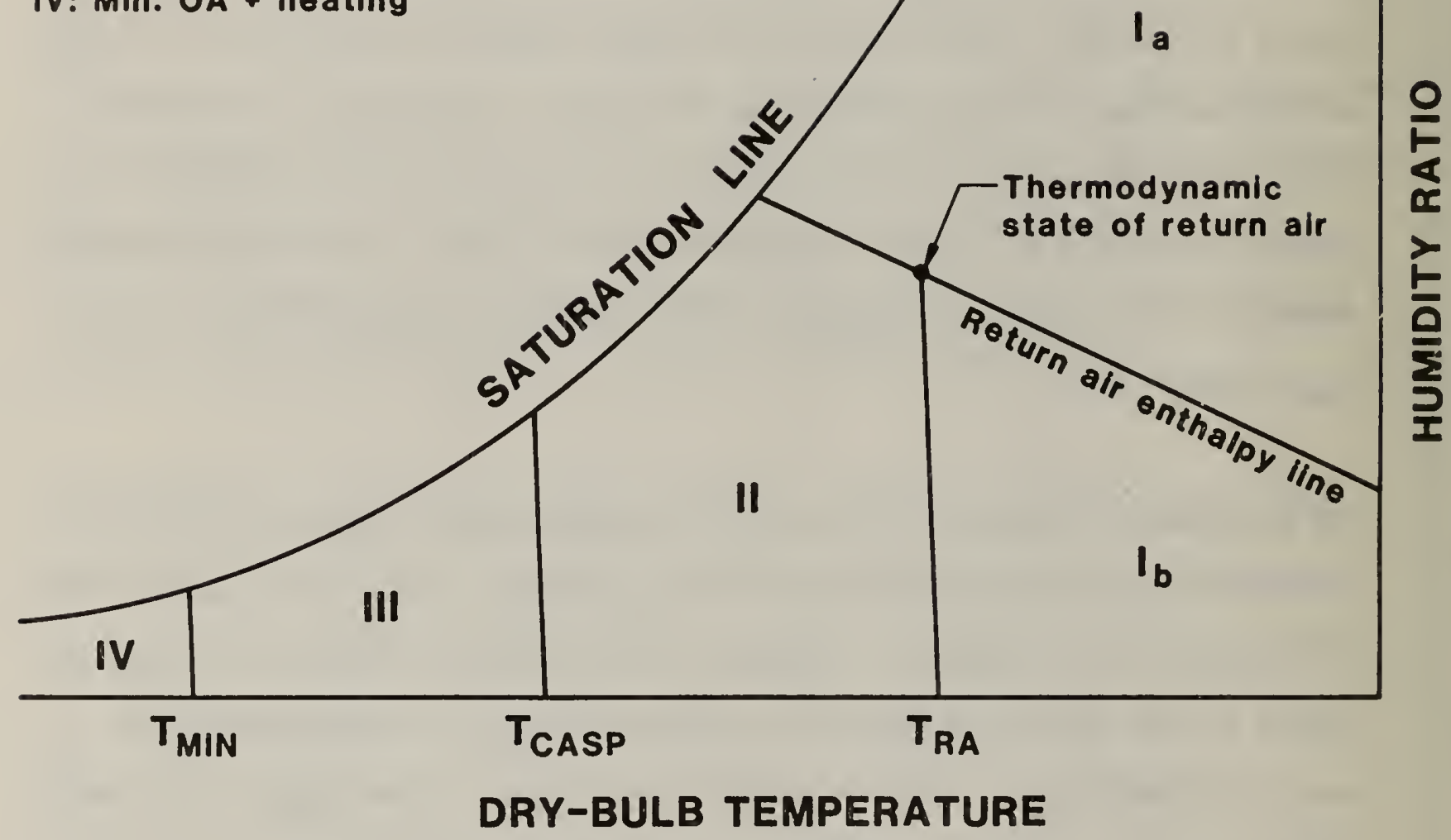

Figure 12. Psychrometric chart of enthalpy economizer cycle for systems which do not employ sprayed cooling coils or air washers 
I: Min. OA + mechanical cooling

II: Max. OA + mechanical cooling

IIl: Mixed $O A$ and $R a$

IV: Min. $O A+$ heating

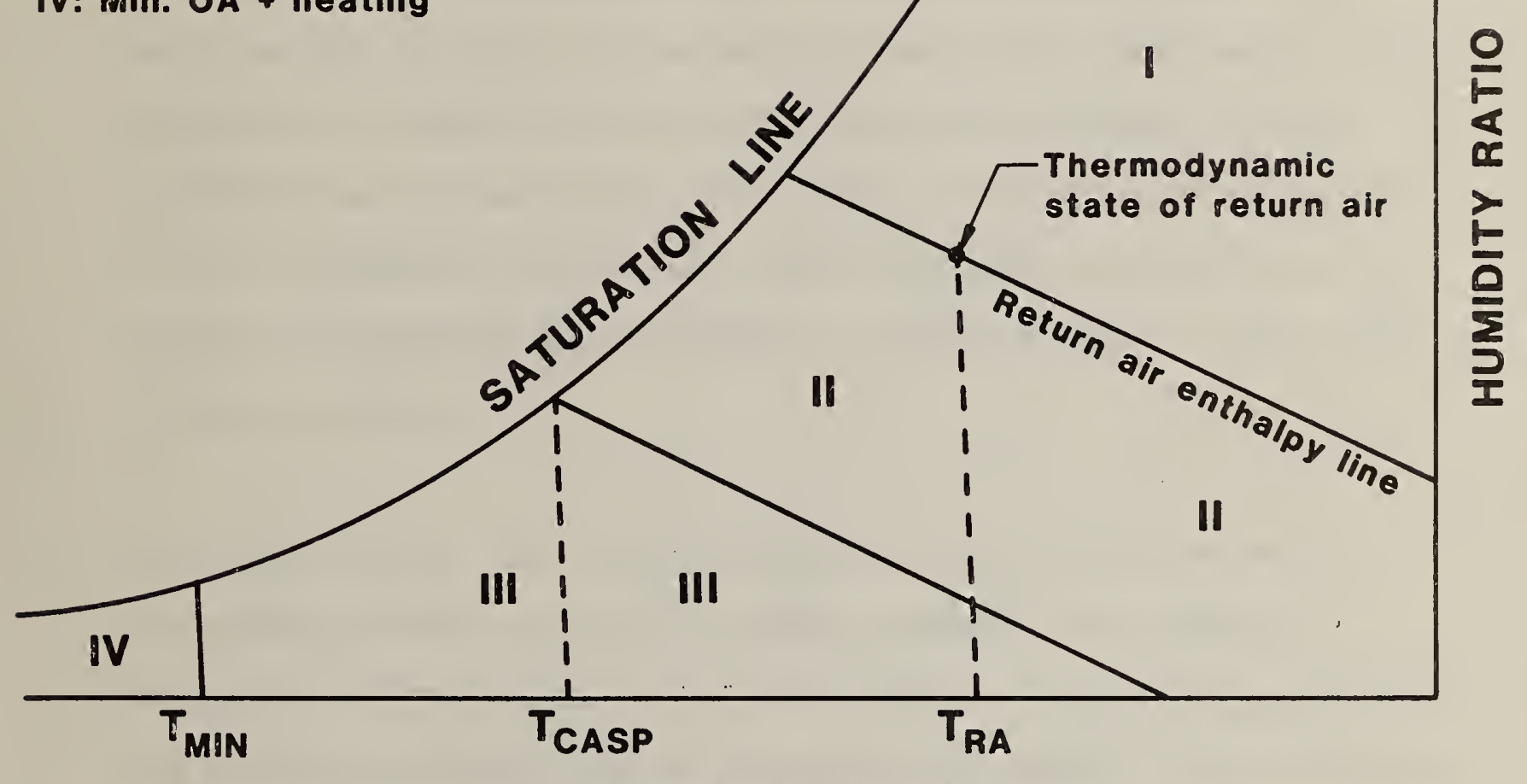

DRY-BULB TEMPERATURE

Figure 13. Psychrometric chart of enthalpy economizer cycle for systems with sprayed cooling coils or air washers 
outside air whenever the outside air enthalpy is less than the enthalpy of the return air but greater than the desired enthelpy of the cooling coil discharge air. 
6. ENTHALPY ECONOMIZER ALGORITHM

The enthalpy economizer may be expressed as follows:

(a) For systems not employing sprayed coils (or air washers), the outdoor, return and relief air dampers should be positioned to admit the minimum amount of outside air (needed to meet the space's minimum fresh air requirements) when either the enthalpy or the dry-bulb temperature of the outside air is greater than or equal to the enthalpy or the dry-bulb temperature of the return air, respectively. For systems using sprayed coils or air washers, the minimum amount of outside air should be used whenever the enthalpy of the outside air is greater than or equal to the return air enthalpy.

(b) The maximum amount of outside air should be used with systems which do not contain sprayed coils (or air washers) whenever the dry-bulb temperature of the outside air is greater than or equal to $\mathrm{T}_{\mathrm{CASP}}$ and both the dry-bulb temperature and the enthalpy of the outside air is less than the dry-bulb temperature, and enthalpy of the return air, respectively. For systems containing sprayed coils (or air washers), the maximum amount of out side air should be used as long as mechanical cooling is required to maintain the cooling coil discharge air temperature, $\mathrm{T}_{\mathrm{CA}}$, at its set

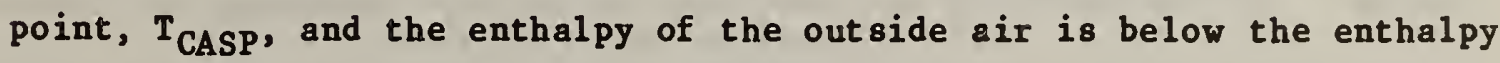
of the return air. 
(c) Controlled mixing of the outside and return air should be done when $\mathrm{T}_{\mathrm{OA}}$ is less than $\mathrm{T}_{\text {CASP }}$ for systems not employing sprayed coils (or air washers) or when mechanical cooling is not required to maintain $\mathrm{T}_{\mathrm{CA}}$ at $T_{\text {CASP }}$ for systems with sprayed coils (or air washers). The mixing should be done to maintain the cooling air discharge temperature, $\mathrm{T}_{\mathrm{CA}}$, at its set point, ${ }^{\mathrm{T}}$ CASP.

(d) For systems with preheating coils, controlled mixing should be overridden and the dampers positioned to admit the minimum amount of outside air when the outdoor air temperature, $\mathrm{T}_{0 A}$, is equal to or below some assigned value $\mathrm{T}_{\mathrm{MIN}}$. The minimum amount of out side air should be that required to meet the minimum fresh air requirements of the conditioned space.

The same points, regarding sequencing and control of the dampers and cooling coil, that were discussed in the section entitled "Dry-Bulb Economizer Algorithm," also apply to the enthalpy economizer cycle. Briefly, if direct digital control is used on a system with a sprayed cooling coil (or an air washer), sequencing of the cooling coil and dampers will require the use of a small control differential or dead zone, $\Delta$, about the set point temperature $\mathrm{T}_{\text {CASP }}$ to prevent excessive switching between control of the cooling coil and control of the dampers. The same $\Delta$ can also be applied to prevent excessive switching between the minimum and maximum open positions of the outdoor damper. For both sprayed coil and non-8prayed coil systems, controlled mixing of the outdoor and return air streams, as well as control of the cooling coil, may also be accomplished using dedicated pneumatic or electronic controllers. 
A logic flow diagram for the enthalpy economizer algorithm described above is presented in figure 14. The input variables to this algorithm are:

\author{
$T_{0 A}$ outdoor air dry-bulb temperature \\ $T_{R A} \quad$ return air dry-bulb temperature \\ $\mathrm{T}_{\mathrm{CA}}$ measured cooling coil discharge air temperature \\ $\mathrm{T}_{\text {CASP }}$ set point value of cooling coil discharge air dry-bulb \\ temperature \\ $T_{M I N} \quad$ specified outdoor air dry-bulb temperature where the minimum \\ position of the outside air damper is reached. \\ $\Delta \quad$ control differential (or dead zone) to minimize the switching \\ frequency of damper or coil valve opening. For simplicity, a \\ single control differential is used for all floating regions \\ in the dry-bulb economizer cycle algorithm in this report. \\ BP measured barometric pressure \\ SPRAY logic variable indicating type of cooling coil, SPRAY = TRUE, \\ if system uses a sprayed coil or air washer, otherwise \\ SPRAI = FALSE otherwise \\ METRIC logical variable indicating whether metric or English units are \\ used, FALSE if English units are used \\ DEWPT logical variable. Set TRUE if outside and return air dew \\ points are measured. Set FALSE if out side and return air \\ relative humidities are measured.
}




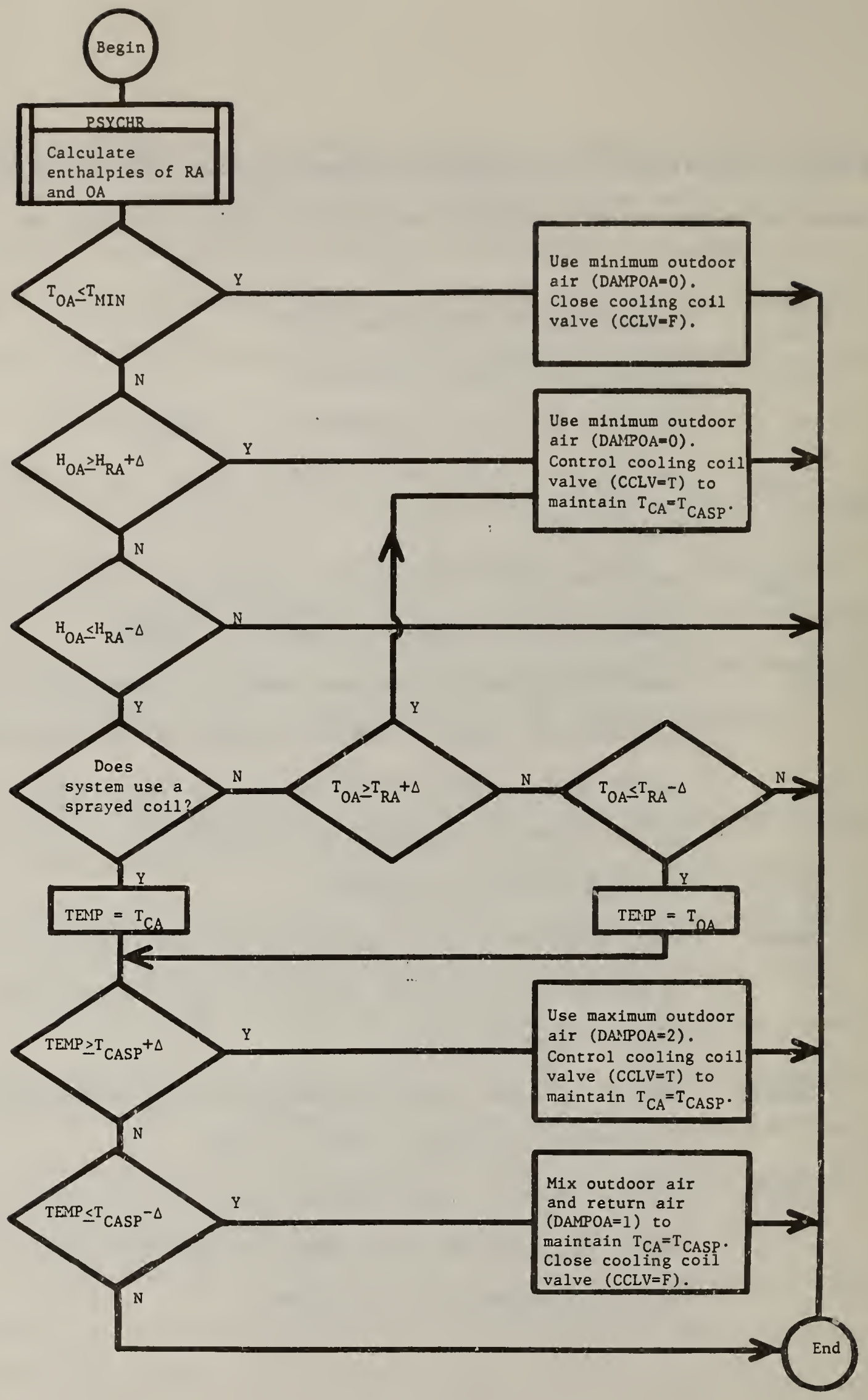

Figure 14. Logic flow diagram of the enthalpy economizer cycle 
In addition, the following measured data are also required:

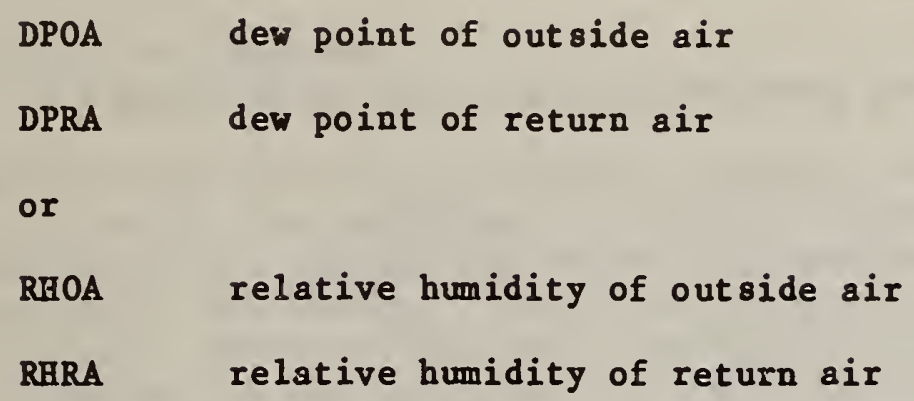

If the HVAC system has recently been started up after the end of an unoccupied period and $\mathrm{T}_{\mathrm{RA}}$ is not near the setpoint temperature of the condition space, then the enthalpy economizer algorithm given above should not be used or should be overridden or supplemented with a building warm-up or cool down control algorithm.

A computer program, called ETCl for this enthalpy economizer algorithm, is presented in Appendix B. A calling routine, ETC1MAIN, and a routine for calculating the required psychrometric properties of moist air (PSYCHR) $[9,10]$ are also listed. Sample input and output are included. 


\section{DUAL-DUCT SYSTEMS}

Dual-duct systems utilize two ducts to distribute the conditioned air to conditioned spaces. One duct delivers chilled air, and the other carries heated air at all times. In order to satisfy the thermal load requirement of the conditioned zone, the hot and cold air is mixed in proper proportion in the mixing box, which is located at each zone. The damper of the mixing box operates in response to the zone thermostat [6]. A basic dual-duct system is shown in figure 5. As briefly mentioned in section 2, dual-duct systems are similar to multi-zone systems. The difference between the two systems is the location where the cold and hot air is mixed. In the multi-zone system, air mixing takes place at the air handling unit and then the mixed air is ducted to various conditioned spaces using a single-duct. In addition, the multizone system has a set of cold and hot deck dampers serving for each zone. These dampers are located at the air handing unit and are controlled by each zone thermostat. Due to similarity of the two systems, only the dual-duct system is discussed in this section.

As shown in figure 5, the outside air and the return air by-pass dampers and are mixed prior to the supply fan. The supply fan delivers the supply air to the hot and cold decks respectively. In the hot deck, the air passing through the heating coil is heated, while the air passing through the cooling coil is chilled in the cold deck. Usually no mechanical cooling is needed during the heating season (winter) and no heating is required during the cooling season 
(summer). The temperature of the mixed air satisfies adequately the zone requirement [6]. But at certain conditions, both heating and cooling operations are required.

Figure 15 depicts the psychrometric chart of a dual-duct system without sprayed coil or air washer. This figure shows the thermodynamic conditions of the air during the cooling season with both heating and cooling coils in operation. The mixed air (MA) temperature is slightly raised to that of the supply air (SA) due to the fan heat gain. The two air streams after the supply air fan are then chilled and heated to the conditions of CA and HA, respectively. In the mixing box, they are mixed to the conditions of zone air (ZA).

When an economizer cycle is applied to the dual-duct system, the cooling energy is reduced by the free cooling of the outside air. However, the overall energy cost of the system may be more wasteful than the system without the economizer cycle, depending on the difference in the unit costs of the cooling and the heating energy, the mass flow ratio of the cold and hot air streams, and the temperature of the hot air (HA). Therefore, an enhancement algorithm for the dual-duct system was developed and is described in the next section. 


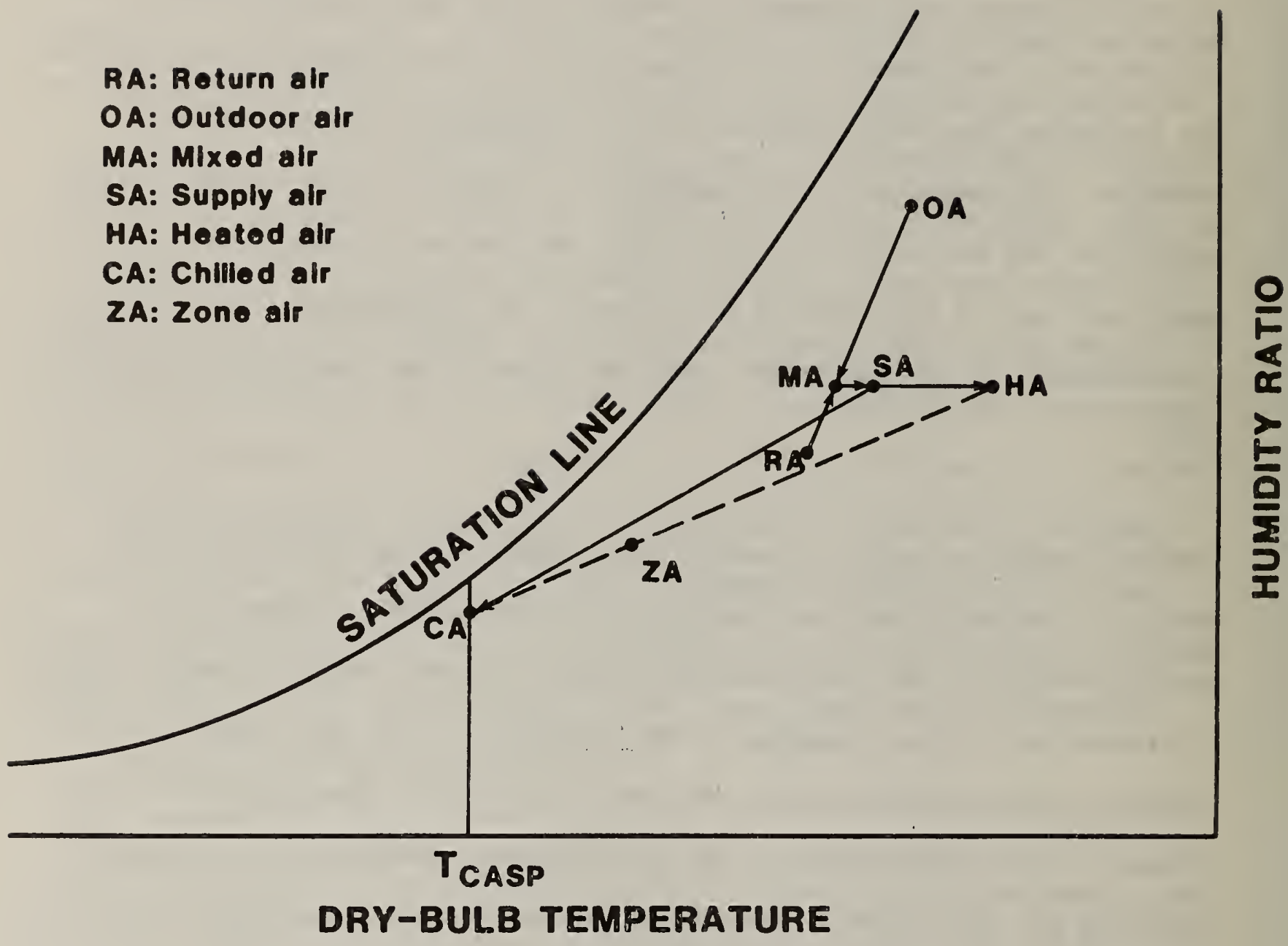

Figure 15. Psychrometric charts of the dual-duct system without sprayed coil or air washer 


\section{ALGORITHM ENRANCEMENT FOR DOAL-DUCT AND MULTI-ZONE SYSTEMS}

The enthalpy economizer algorithm presented in section 6 assumes that the heating cost is the same as the cooling cost for the same amount of energy used. The correctness of this assumption has no effect on single-zone systems. But a more complex evaluation of the system operation is needed for the dual-duct and multi-zone systems to determine the overall energy effect of the enthalpy economizer operation. The enhancement algorithm described in this section is an optional procedure which supplements the enthalpy economizer algorithm presented previously. Application of the optional enhancement requires the input of additional information which will be described later.

As seen in figure 12, when the enthalpy economizer is employed to a singlezone system, the use of a minimum amount of outdoor air is economical if the thermodynamic state of outdoor air is in region $I$, and admitting the maximum amount of outdoor air is cost-saving if the psychrometric property of the outdoor air is in region II. This statement is not always true for dual-duct and multi-zone systems. The optional procedure introduces a dimensionless factor, $\lambda$, to be used to compare the energy costs of the system in these two regions. The factor $\lambda$ is defined as the ratio of the total energy cost (cooling and heating) of the air-handling system with the outside air damper at the minimum opening position to that with the damper at its maximum opening position. The derivation of $\lambda$ may be found in Appendix C. 
In regions I and II, a decision based on the cost evaluation of $\lambda$ replaces the decision made by the enthalpy algorithm described previously. If $\lambda$ is greater than 1.0, the maximum amount of outside air is allowed to enter the system. Otherwise, the minimum amount of outside air is admitted. When the psychrometric condition of the outside air is in regions III and IV, no cost evaluation is performed and the algorithm described previously applies. The logic flow diagram of the enhancement routine is shown in figure 16 . This cost comparison routine incorporates the enthalpy economizer algorithm, ETCl, and requires the following additional data:

$\cos T$ logical variable indicating whether cost evaluation is desired $(\cos T=$ TROE $)$, or $\operatorname{not}(\cos T=$ FALSE $)$.

$\mathrm{T}_{\mathrm{HA}}$ dry-bulb temperature of heating coil discharge air

$\mathrm{X}_{\mathrm{CA}} \quad$ ratio of cooling coil air flow rate to supply air flow rate

$\mathrm{X}_{\mathrm{HA}}$ ratio of heating coil air flow rate to supply air flow rate

$\mathrm{X}_{\text {OAMIN }}$ ratio of minimum outside air flow rate

to supply air flow

HGTOCL cost ratio of heating energy to cooling energy for the same amount of energy

$$
=\frac{\$ \text { of heating per Btu or } \mathrm{KJ}}{\$ \text { of cooling per BCu or } \mathrm{KJ}}
$$

DPCA dew point of cooling coil discharge air

DPHA dew point of heating coil discharge air

or

RHCA relative humidity of cooling coil discharge air

RHHA relative humidity of heating coil discharge air 


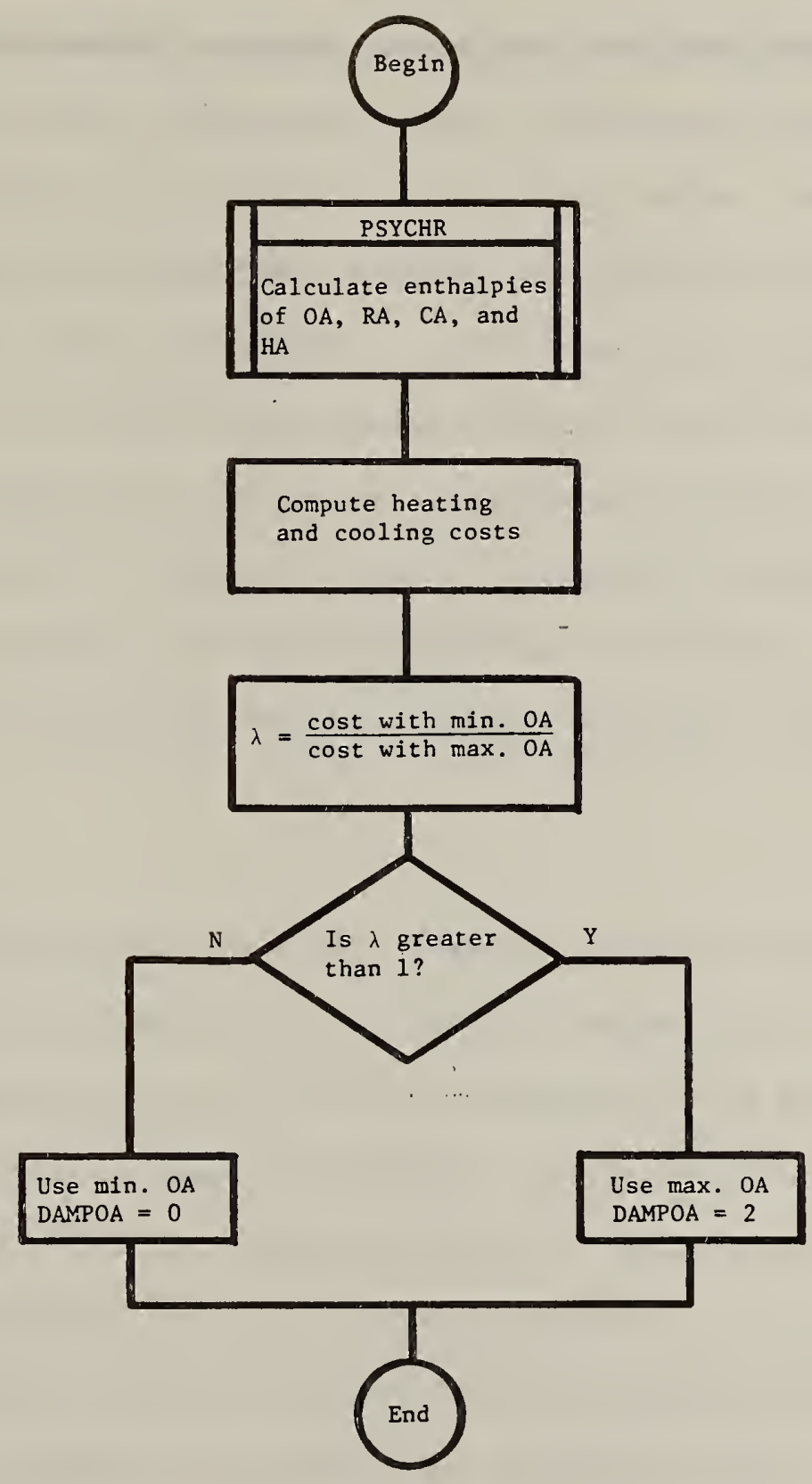

Figure 16. Logic flow diagram of the enhancement routine for dual-duct system 
A computer program, ETC2, of the enthalpy economizer algorithm incorporating the optional enhancement reoutine (HCCOST) is given in Appendix D. Sample input and output are included. When the logical value of COST is false, the program ETC2 performs the same role as the program ETCl, and the logical flow becomes identical. 


\section{SUMMARY}

Commonly used air handling systems were briefly reviewed in this report. These systems included single-zone, reheat, variable air volume, and dual-duct types having either dry cooling coils or sprayed coils. Energy Management and Control Systems often incorporate dry-bulb or enthalpy economizer cycles in order to reduce energy consumption. In this study, the psychrometric chart of atmospheric air was divided into various regions, using the psychrometric states of the return air, cooling coil discharge air, supply air, and other pertinent parameters. Algorithms were developed for an EMCS to determine the amount of outside air to be admitted into the air handling systems for outside air conditions in the different regions and the types of coils used (dry or sprayed).

For the economizer cycles based upon measured dry-bulb temperatures, the algorithms require values of the out side air temperature, a specified changeover temperature and its control differential, the actual and setpoint temperatures of the cooling coil discharge air, a specified outdoor air temperture below which the minimum position of the outside air damper is to be used, and knowledge of the type of cooling coil (dry or sprayed). For the enthalpy economizer cycle, the changeover and out side air temperatures in the above list are replaced by the return air temperature and outside air enthalpy, respectively. In addition, the return air humidity is also required. 
Since the energy avings of dual-duct and multi-zone gystems are complicated by the relative costs of beating energy and cooling energy, an enhancement algorithm for these system was also developed which utilized the relative costs of heating and cooling energies and the mass flow rates of the heating and cooling air.

Computer program8, written in Portran 77, were presented in the appendices to assist the reader in implementing these algorithm. 


\section{REFERENCES}

[1] Shavit, G., "Enthalpy Control Systems Increased Energy Conservation," Handbook of Energy Conservation for Mechanical Systems in Buildings, edited by R. W. Roose, Van Nostrand Reinhold Co., 1978, pp. 449-460.

[2] Parken, W.H., KaO, J.Y., and Relly, G. E., "Strategies for Energy Conservation in Small Office Buildings," Natl. Bur. of Standards, NBSIR 82-2489, June 1982.

[3] Rao, J.Y., Parken, W.H., and Pierce, E.T., "Strategies for Energy Conservation for a Large Retail Store," Natl. Bur. of Standards, NBSIR 82-2580, Sept. 1982.

[4] Rao, J.Y., and Pierce, E.T., "A Study of Sensor Errors on Building Energy Consumption", 7th Energy Management and Control Soc. Conf., Salt Lake City, Jtah, Nov. 14-17, 1982.

[5] ASHRAE, System Handbook, Chapter 3, 1980.

[6] Haines, R.W., Control Systems for Heating, Ventilating and Air Conditioning, 3rd ed., Van Nostrand Reinhold, 1983.

[7] Croome, D.J., and Roberts, B.M., Air Conditioning and Ventilation of Buildings, 2nd ed., Vo1 1, Pergamon Press, 1981.

[8] Honeywel1, Energy Conservation with Comfort, 2nd ed., 1979

[9] Brokaw, R.S., "Calculation of Flue Losses for High-Efficiency Furnaces and Appliances," ASHRAE Journal, Jan. 1979, pp. 49-51.

[10] ASHRAE, Fundamentals Handbook, Chapter 5, 1981. 

APPENDIX A. COMPUTER PROGRAM LISTING OF THE DRY BULB ECONOMIZER

ALGORITHM (DBE), AND SAMPLE INPUT AND OUTPUT

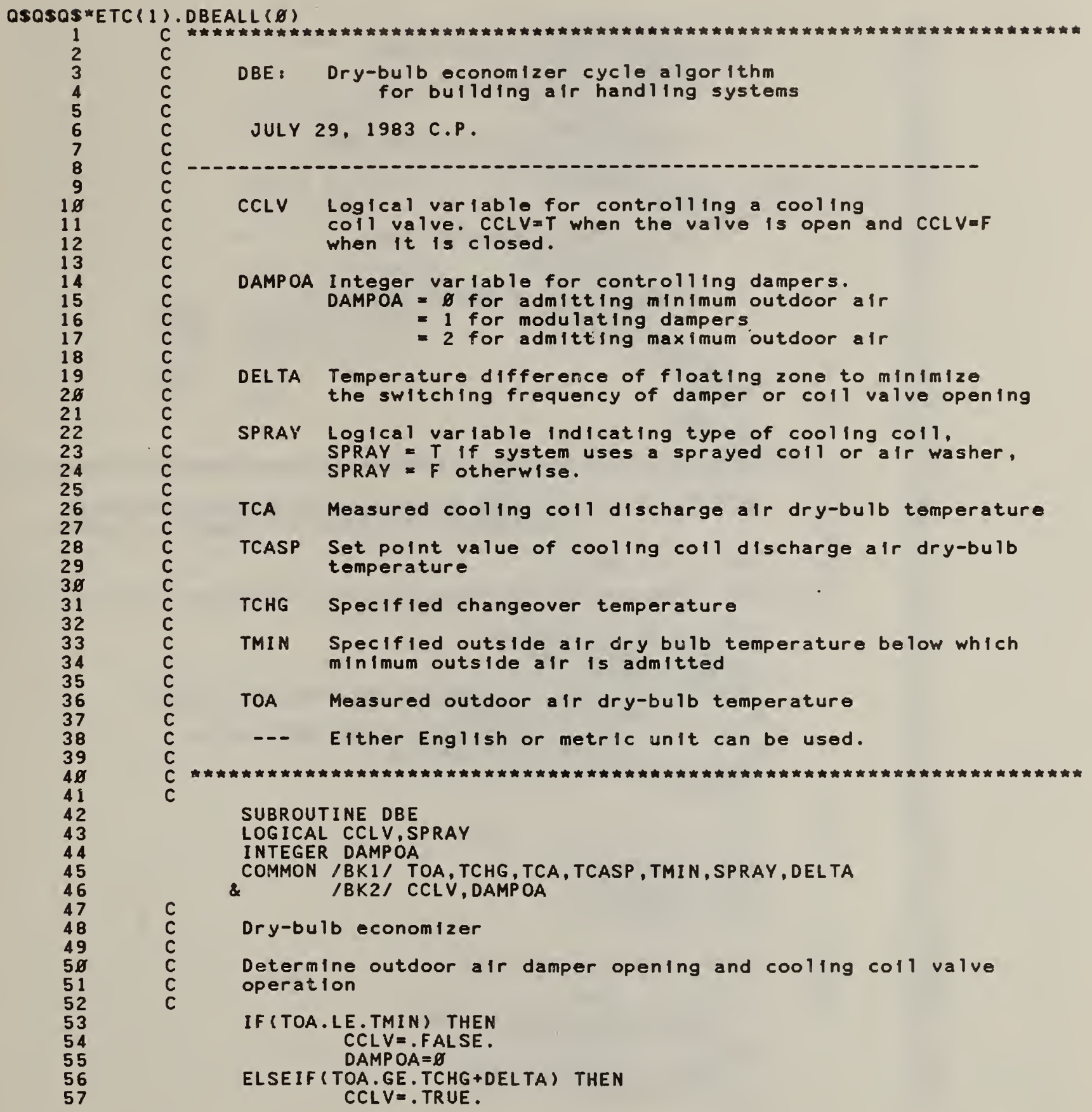


DAMPOA $=\varnothing$

ELSE IF (TOA. LE.TCHG-DELTA) THEN IF (SPRAY) THEN

IF (TCA.GE . TCASP + DELTA) THEN CCLVE.TRUE.

$D A M P O A=2$

ELSEIF (TCA. LE.TCASP-DELTA) THEN CCLVE.FALSE.

ELSE DAMPOA=1

IF (TOA,GE, TCASP + DELTA) THEN

CCLVE. TRUE.

DAMPOA $=2$

ELSEIF (TOA. LE.TCASP-DELTA) THEN

CCLVE. FALSE.

ENDIF

DAMPOA=1

C

ENDIF

END

$c$
$C$
$C$
$C$
$C$
$C$
$C$
$C$
$C$

$c$
$c$
$c$
$c$
$c$
$c$
$c$
$c$

* * *

DBEMAIN I Main program to call the dry-bulb economizer

algorithm for bullding air handiling systenis

JULY 29,1983 C.P.

CHARACTER TITLE( 2$) * 8 B$

LOGICAL CCLV, SPRAY

INTEGER DAMPOA

COMMON /BKI/ TOA, TCHG, TCA, TCASP, TMIN, SPRAY, DELTA

\& /BK2/ CCLV, DAMPOA

NAMELIST /INPUT/ SPRAY,TCHG, TCASP, TMIN, DELTA

$\&$ OPEN $7, F$ ILE-'DBEDATA')

$c$
$C$ REWIND 7

Read initial input data

READ (7, 10ஜØ) TITLE

READ ( 7, INPUT)

PRINT I.⿴囗ठ, TITLE

PRINT INPUT

C

c

Read measured input data

IF (SPRAY) THEN

READ (7, * END=999) TOA, TCA

ELSE

2880, TOA, TCA

READ (7, , END $=999)$ TOA

PRINT 2080, TOA

ENDIF 


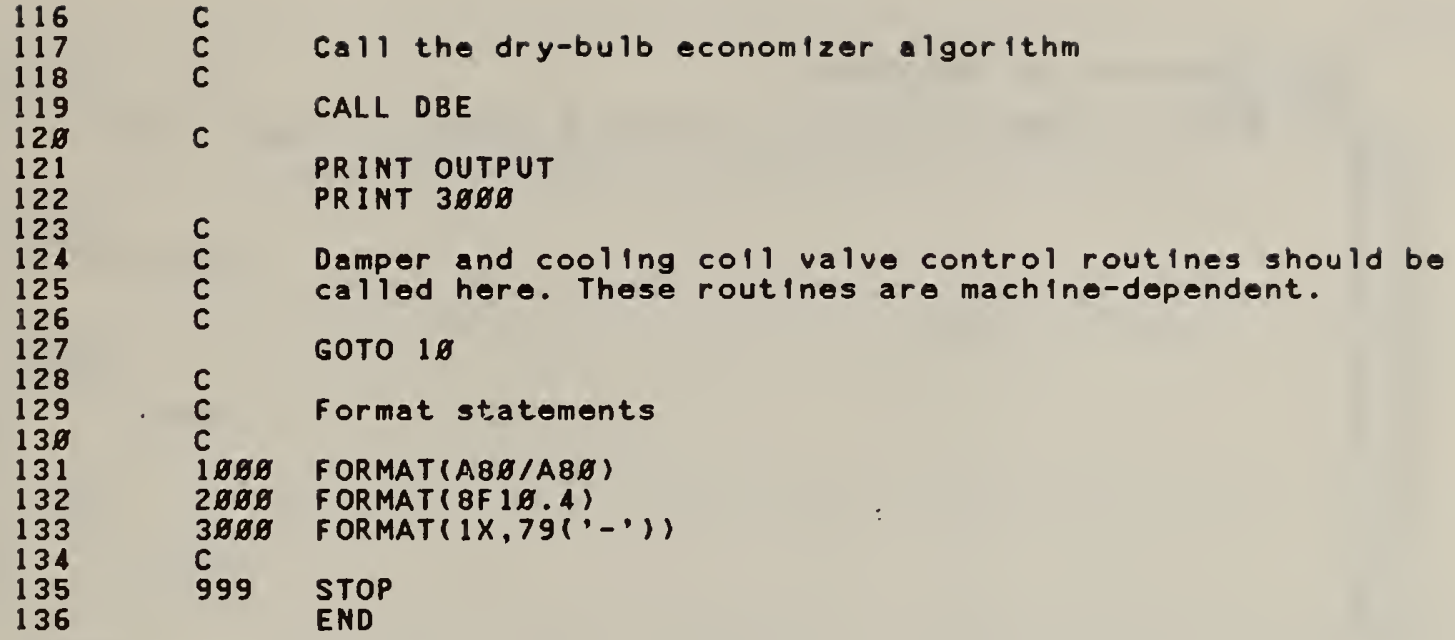




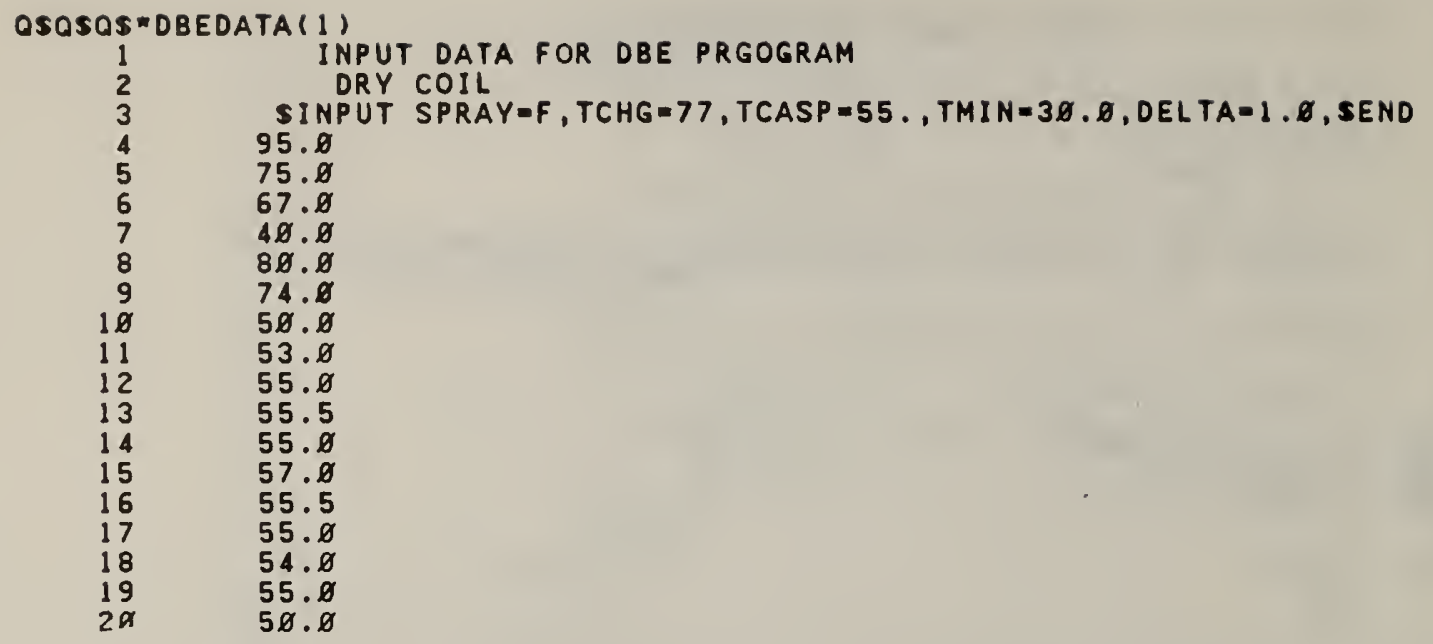

\section{QXOT ETC.DBES}

INPUT DATA FOR DBE PRGOGRAM

DRY COIL SINPUT SPRAY
SEND

95.8 .8 .80

SOUTPUT

$C C L V=T, D A M P O A=\varnothing$

SEND

75.0 .000

SOUTPUT

$C C L V=T, D A M P O A=$

\$END

67.0 .000

SOUTPUT

$C C L V=T, D A M P O A=$

SEND

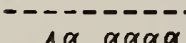

\$OUTPUT

$C C L V=F, D A M P O A=$

SEND

80.0000

\$OUTPUT

CCLV $=T$, DAMPOA $=$

\$END

74.0 .800

SOUTPUT

$C C L V=T, D A M P O A=$ SEND

2

- - - - - - - - - - - - - - - - - - - - - - - - - - - - - - - - - - - - - -

2

(1)


58.

SOUTPUT

SEND

1

$---1-1-10$

SOUTPUT

$C C L V=F, D A M P O A=$

SEND

55.0000

SOUTPUT

$C C L V=F, D A M P O A=$

SEND

1

52.5000

SOUTPUT

$C C L V=F, D A M P O A=1$

SEND

55.0000

SOUTPUT

$C C L V=F, D A M P O A=$

SEND

57.0000

SOUTPUT

CCLV = T, DAMPOA

SEND

55.5000

SOUTPUT

$C C L V=T, D A M P O A=2$

SEND

55.0000

SOUTPUT

CCLV $=T, D A M P O A=$

\$END

54.0000

\$OUTPUT

$C C L V=F, D A M P O A=$

SEND

52.0000

SOUTPUT

$C C L V=F, D A M P O A=$

SEND

50.0000

\$OUTPUT

$C C L V=F, D A M P O A=$

SEND

2

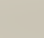

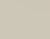



APPENDIX B. COMPUTER PROGRAM LISTING OF THE ENTHALPY ECONOMIZER ALGORITHM (ETC1), AND SAMPLE INPUT AND OUTPUT

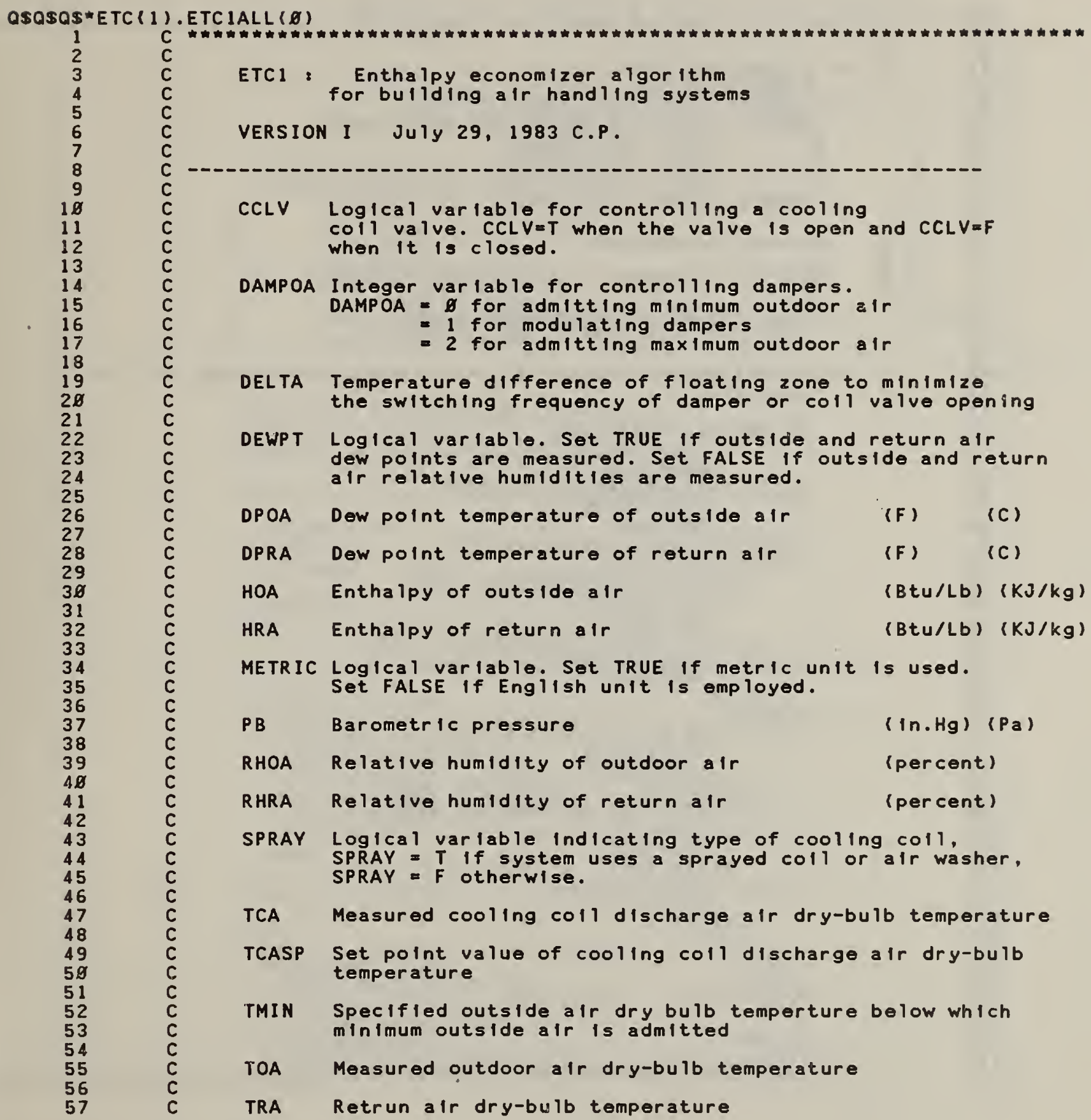




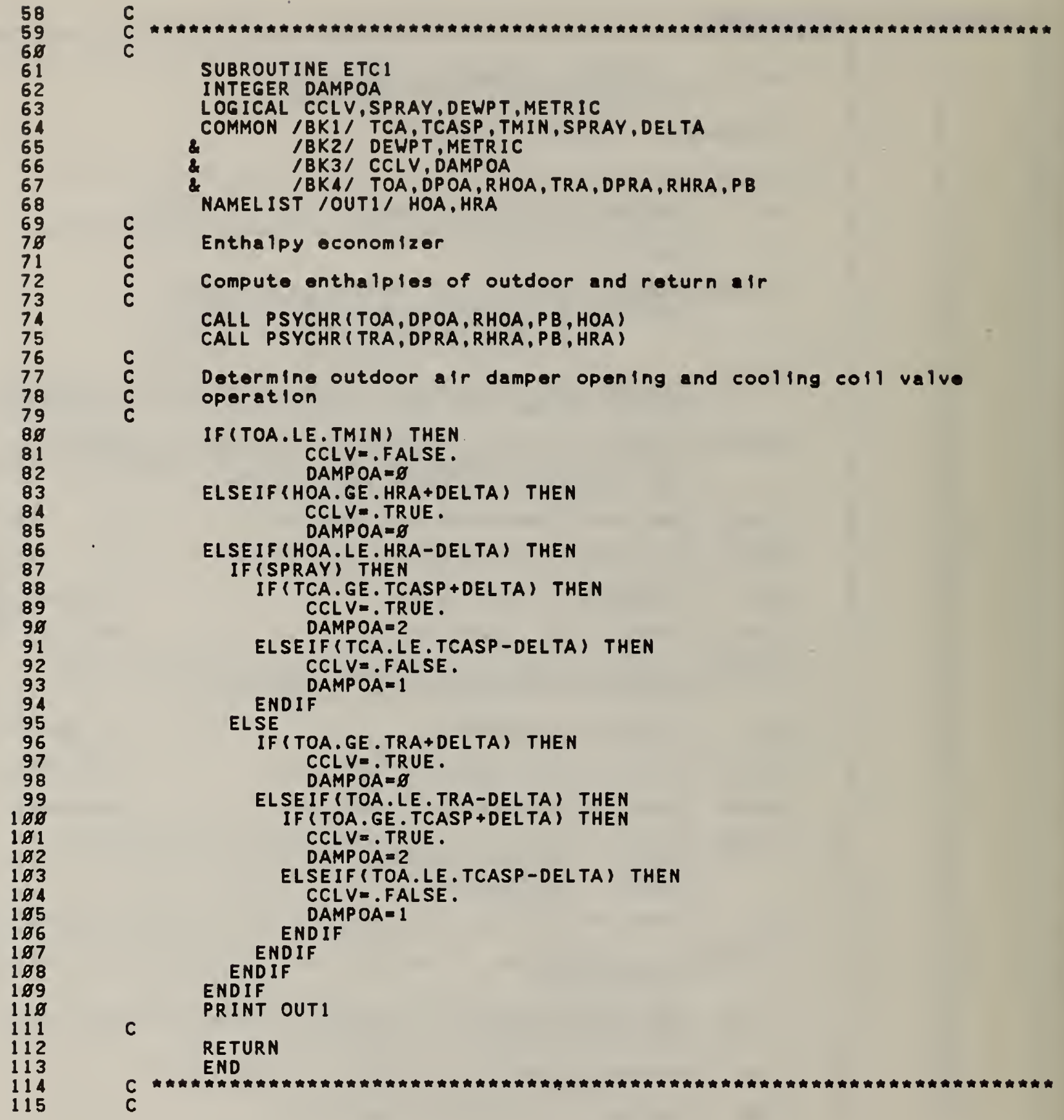




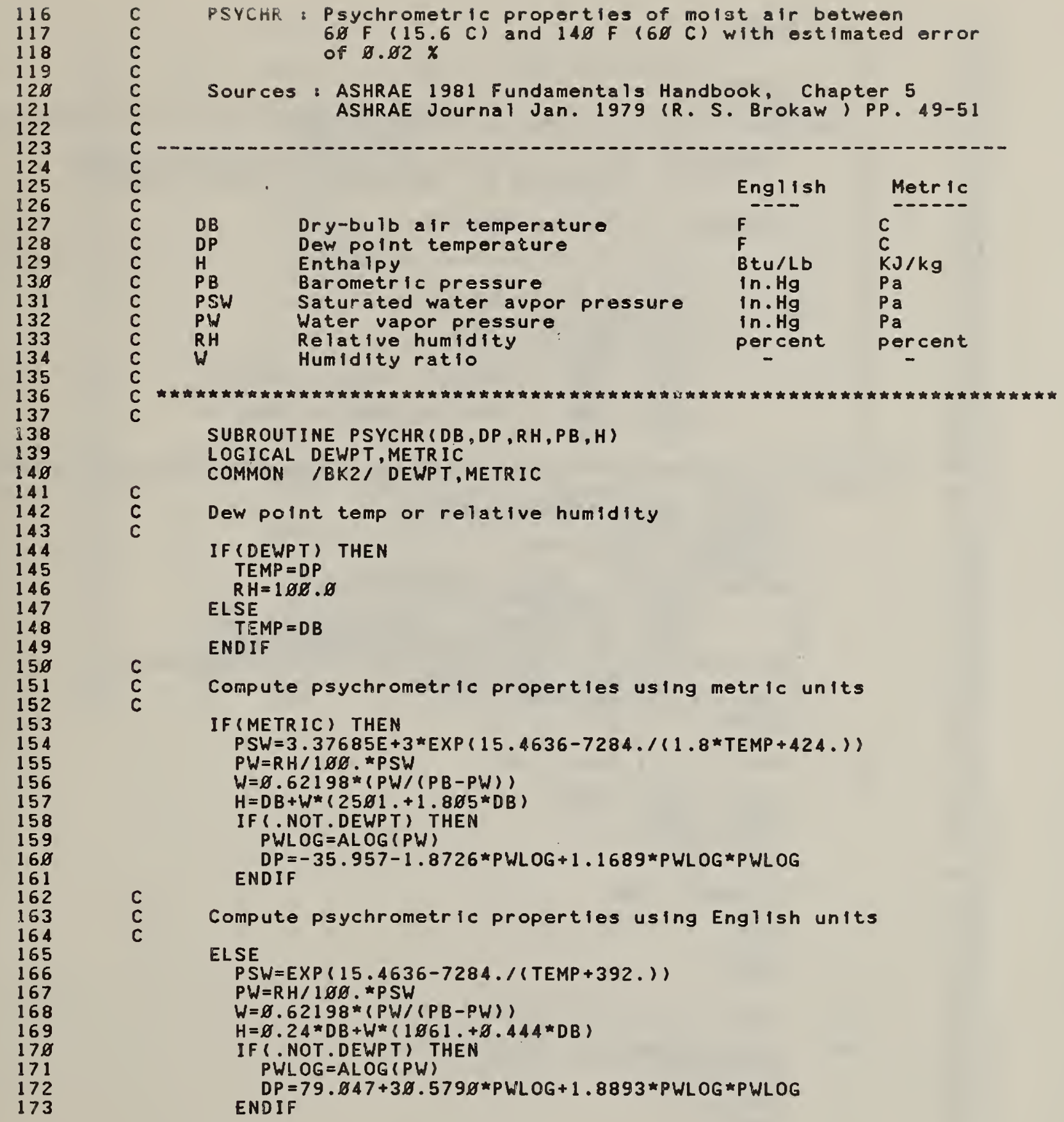




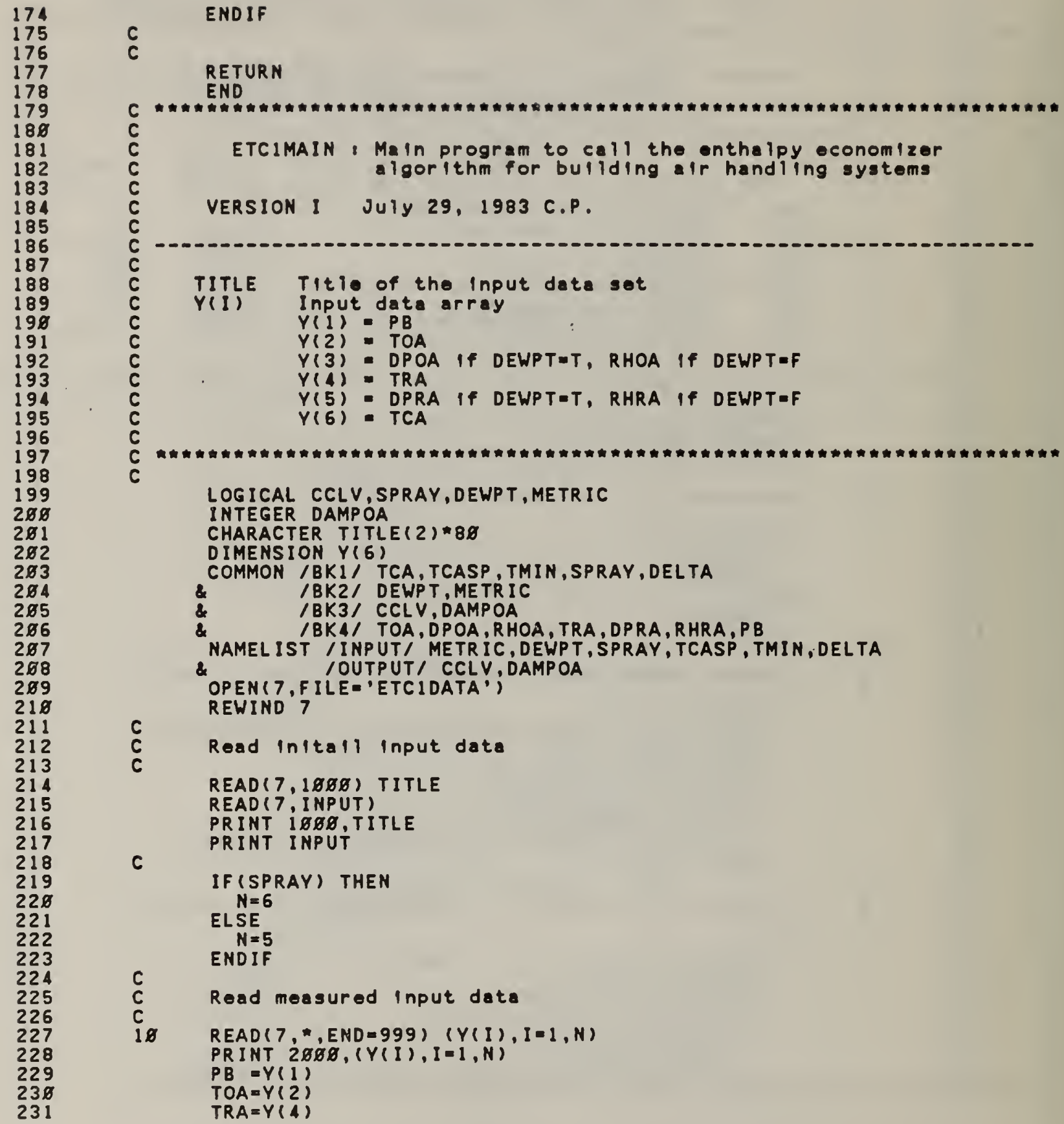




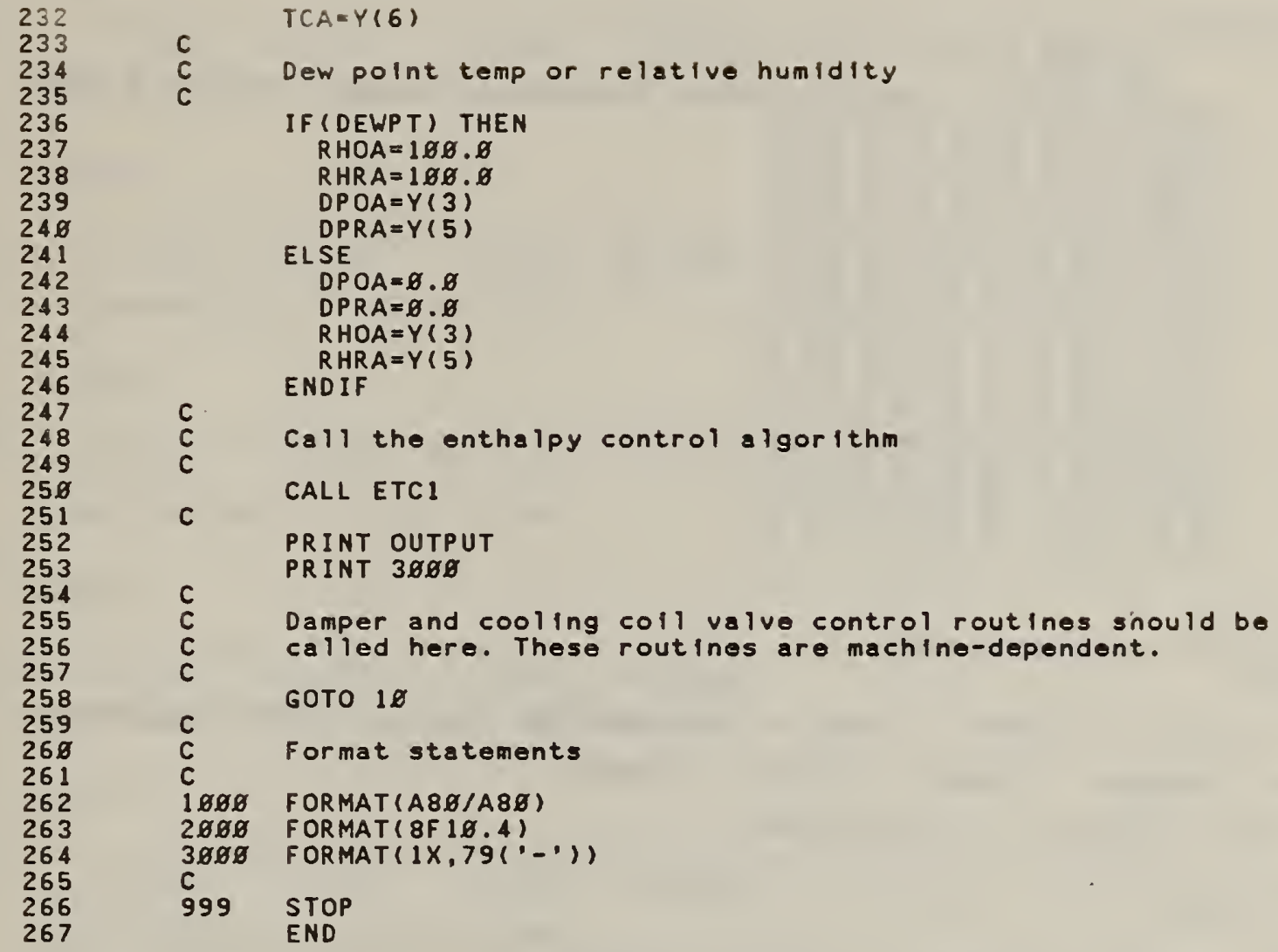




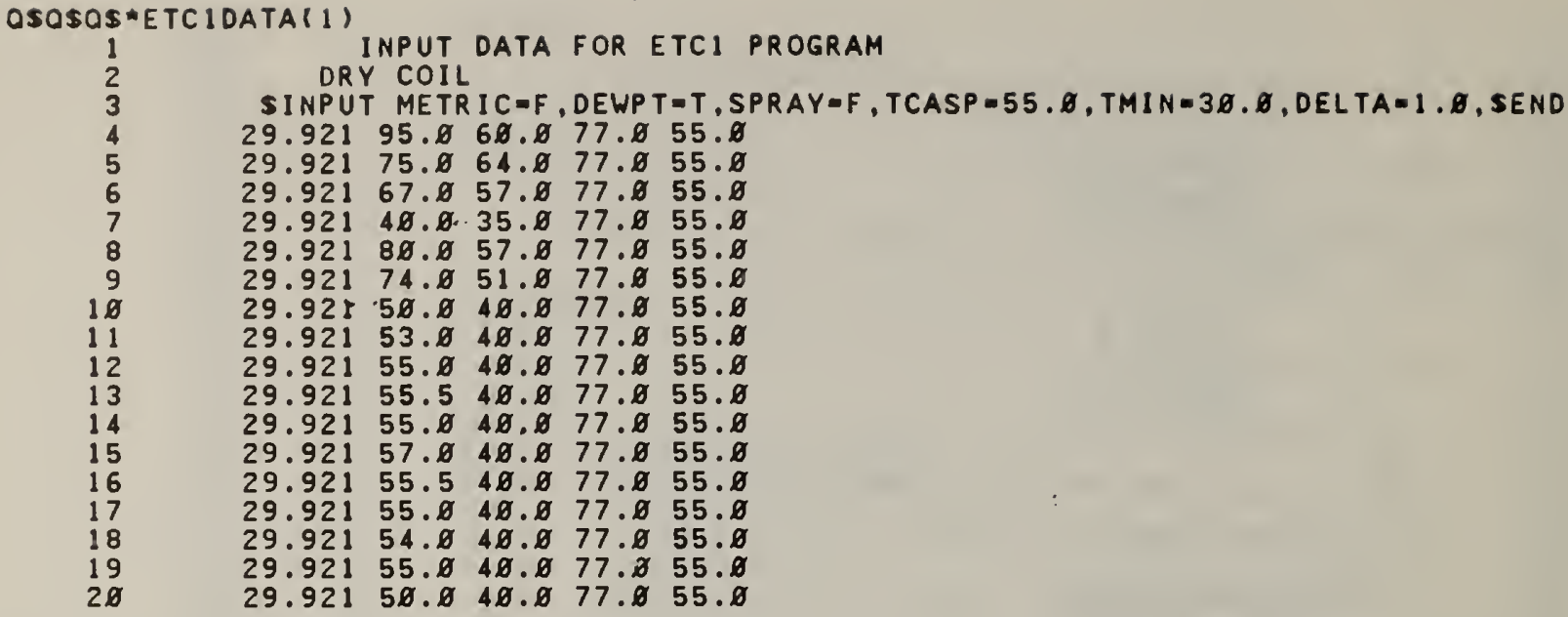

EXOT ETC.ETCIS

INPUT DATA FOR ETCI PROGRAM

DRY COIL SINPUT

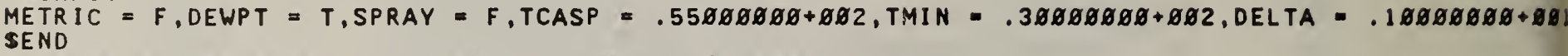

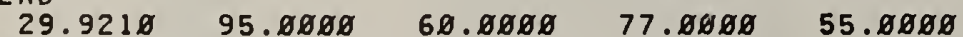
SOUT1

$H O A=.34966373+862, H R A=.28536576+\varnothing 82$

SEND

SOUTPUT

$C C L V=T, D A M P O A=$

SEND

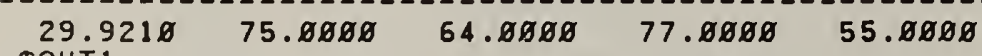

SOUT1

$\mathrm{HOA}=.31938431+862, \mathrm{HRA}=.28536576+862$

\$END

SOUTPUT

$C C L V=T, D A M P O A=$

SEND

$$
29.9210 \quad 67.0000 \quad 57.0680 \quad 77.0000 \quad 55.0000
$$

\$OUT 1

HOA $=.268618280+862, H R A=.28536576+862$

\$END

SOUTPUT

$C C L V=T, D A M P O A=$

\$END

$29.9210 \quad 46.0000 \quad 35.000077 .0000655 .0000$ SOUT 1

HOA $=.14181454+\varnothing 62, H R A=.28536576+\varnothing 62$

\$END

SOUTPUT 


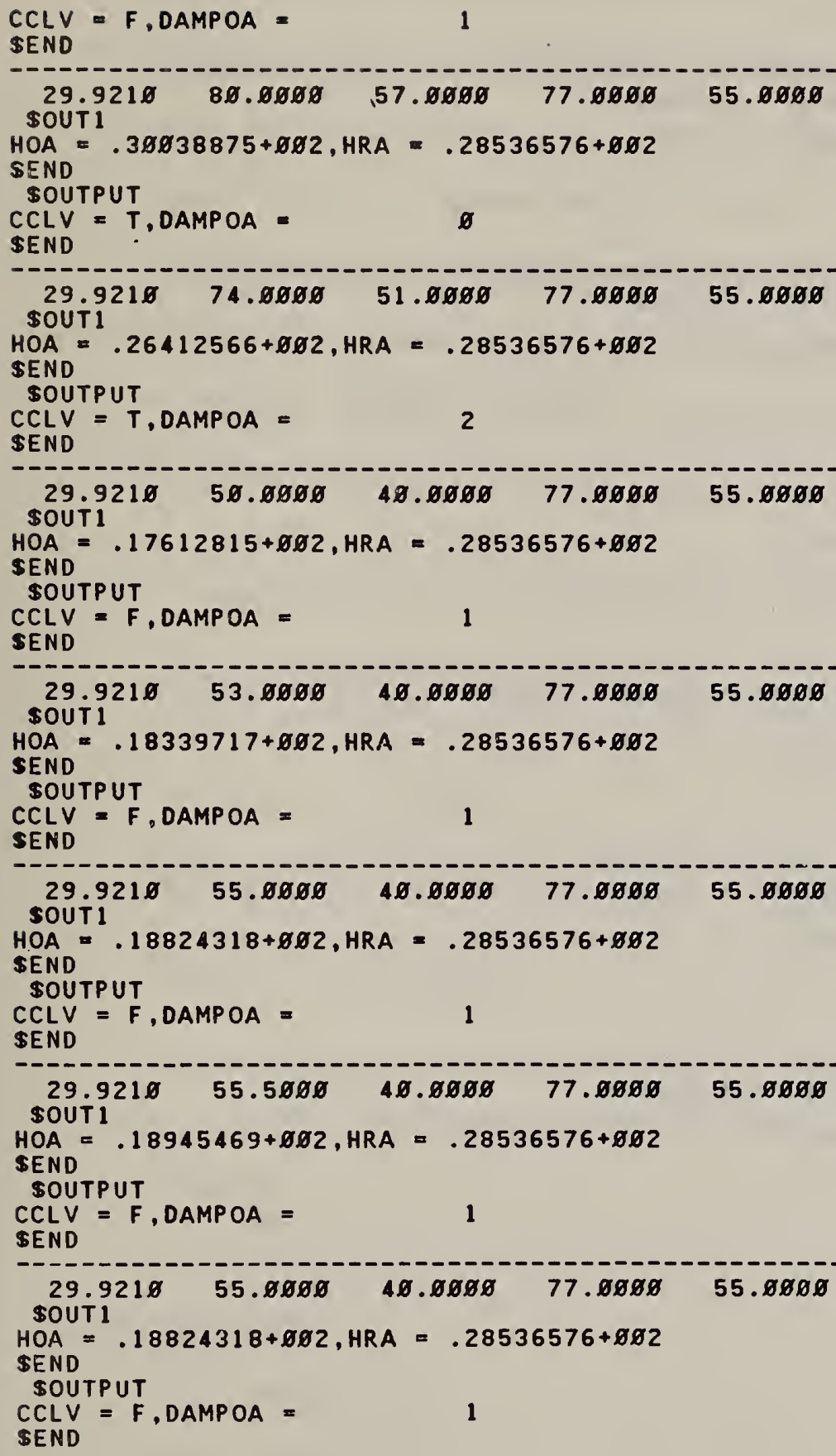




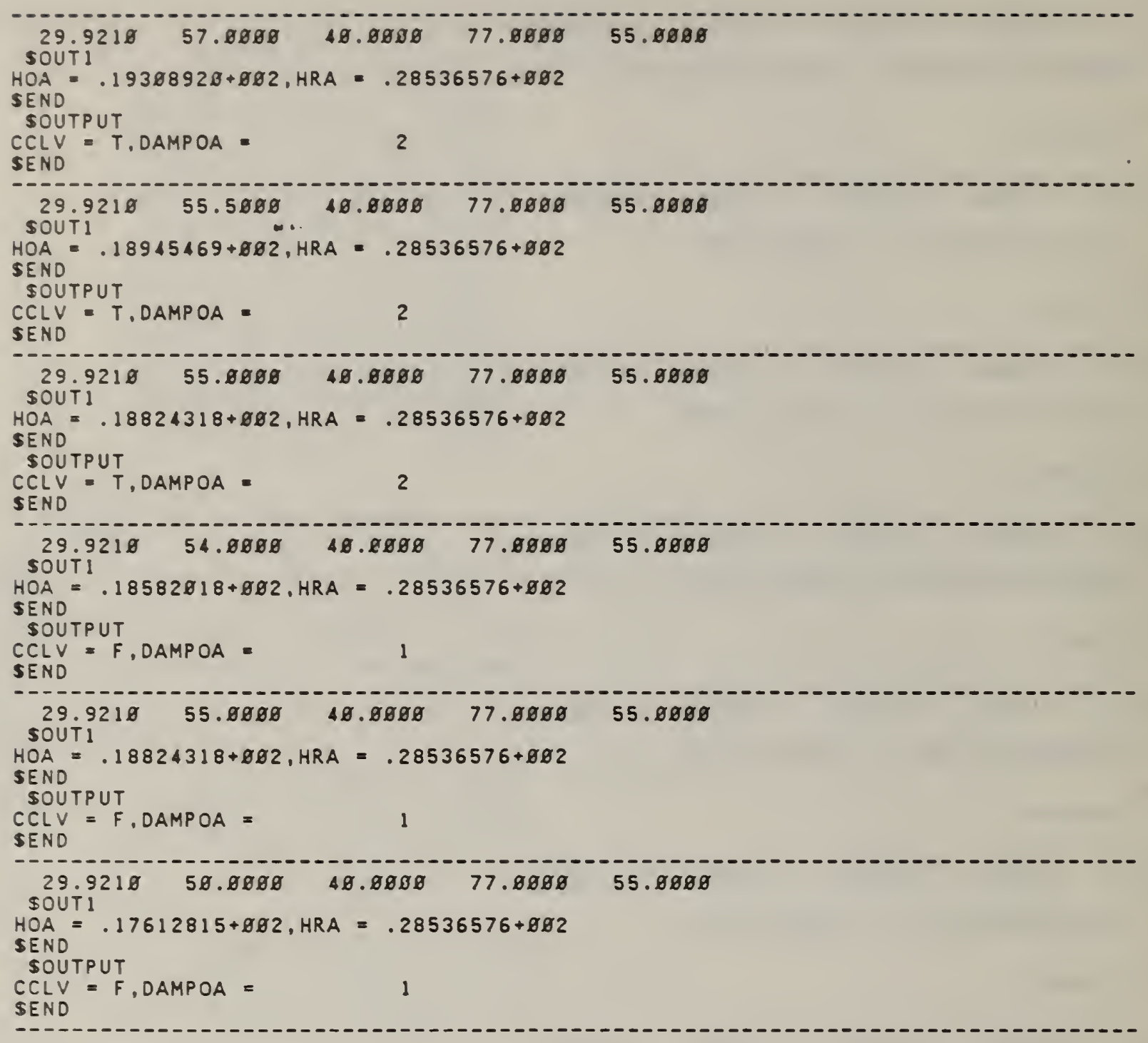


APPENDIX C. DERIVATION OF THE DIMENSIONLESS FACTOR, $\lambda$

For dual-duct and multi-zone systems, the basic enthalpy economizer algorithm described in section 6 is modified to take into account the differences in the costs of heating energy and cooling energy. This is discussed in sections 7 and 8 . A dimensionless factor, $\lambda$, is introduced as the ratio of the total energy cost (cooling and heating) of the air-handling system with the outside air damper at the minimum opening position to that with the damper at the maximum opening position. The derivation of $\lambda$ is presented here (see figures 5 and 14 ).

Energy equations for the system shown in figure 5 are as follows:

$$
\begin{aligned}
& m_{O A} h_{O A}+m_{R A} h_{R A}=m_{M A} h_{M A} \\
& m_{M A} h_{M A}+q_{F}=m_{S A} h_{S A} \\
& m_{H A} h_{S A}+q_{H}=m_{H A} h_{H A} \\
& m_{C A} h_{S A}+q_{C}=m_{C A} h_{C A}
\end{aligned}
$$

where $m, h$, and $q$ represent mass flow rate, enthalpy, and heat flow rate, respectively.

Subscripts are:

OA: outdoor air

RA: return air

MA: mixed air

$\mathrm{CA}$ : the air leaving the cooling coil 
HA: the air leaving the heating coll

SA: supply air

C: cooling coll

H: heating coll

F: supply fan

Assume that $\mathrm{q}_{F}$ is negligible $\left(\mathrm{q}_{F} \simeq 0\right)$, and that the mass of added or removed moisture is negligible with respect to air mass. Applying the mass conservation principle, heat flow rates for heating and cooling can be expressed, from equations (1) through (4), as:

$$
\begin{aligned}
& q_{H}=m_{H A} h_{H A}-\left(m_{H A} / m_{S A}\right)\left(m_{O A} h_{O A}+m_{R A} h_{R A}\right) \\
& q_{C}=m_{C A} h_{C A}-\left(m_{C A} / m_{S A}\right)\left(m_{O A} h_{O A}+m_{R A} h_{R A}\right)
\end{aligned}
$$

When the outside air damper is positioned to admit the minimum amount of outdoor air,

$$
\begin{aligned}
& m_{R A}=m_{S A}-m_{O A, m i n} \\
& m_{O A}=m_{O A, \text { min }}
\end{aligned}
$$

where $m_{0 A}$, min is the mass flow rate of the outside air with its damper at the minimum opening position.

When the outside air damper is positioned at its maximum opening,

$$
\begin{aligned}
& m_{R A}=0 \\
& m_{O A}=m_{S A}
\end{aligned}
$$


Substituting equations (7) and (8) into (5) and (6), we obtain:

$$
\begin{aligned}
& \mathrm{q}_{\mathrm{H}, \text { min }}=\mathrm{m}_{\mathrm{HA}} \mathrm{h}_{\mathrm{HA}}-\left(\mathrm{m}_{\mathrm{HA}} / \mathrm{m}_{\mathrm{SA}}\right)\left[\mathrm{m}_{\mathrm{OA}, \min } \mathrm{h}_{\mathrm{OA}}+\left(\mathrm{m}_{\mathrm{SA}}-\mathrm{m}_{\mathrm{OA}, \mathrm{min}}\right) \mathrm{h}_{\mathrm{RA}}\right] \\
& { }_{\mathrm{C}, \text { min }}=\mathrm{m}_{\mathrm{CA}} \mathrm{h}_{\mathrm{CA}}-\left(\mathrm{m}_{\mathrm{CA}} / \mathrm{m}_{\mathrm{SA}}\right)\left[\mathrm{m}_{\mathrm{OA}, \min { }^{\mathrm{O}} \mathrm{OA}}+\left(\mathrm{m}_{\mathrm{SA}}-\mathrm{m}_{\mathrm{OA}, \mathrm{min}}\right) \mathrm{h}_{\mathrm{RA}}\right]
\end{aligned}
$$

Similarly, with the damper at maximum position, the heat flow rate equations become :

$$
\begin{aligned}
& \mathrm{q}_{\mathrm{H}, \max }=\mathrm{m}_{\mathrm{HA}}\left(\mathrm{h}_{\mathrm{HA}}-\mathrm{h}_{\mathrm{OA}}\right) \\
& \mathrm{q}_{\mathrm{C}, \max }=\mathrm{m}_{\mathrm{CA}}\left(\mathrm{h}_{\mathrm{CA}}-\mathrm{h}_{\mathrm{OA}}\right)
\end{aligned}
$$

We can normalize equations (11) through (14) by $\mathrm{m}_{\mathrm{SA}}$. From equations (11) and (12), we have

$$
\begin{aligned}
& \mathrm{q}_{\mathrm{H}, \min }^{\prime}=\mathrm{x}_{\mathrm{HA}} \mathrm{h}_{\mathrm{HA}}-\mathrm{x}_{\mathrm{HA}}\left[\mathrm{x}_{\mathrm{OA}, \min }{ }^{\mathrm{h}} \mathrm{OA}+\left(1-x_{\mathrm{OA}, \min }\right) \mathrm{h}_{\mathrm{RA}}\right] \\
& \mathrm{q}_{\mathrm{C}, \min }^{\prime}=\mathrm{x}_{\mathrm{CA}} \mathrm{h}_{\mathrm{CA}}-\mathrm{x}_{\mathrm{CA}}\left[\mathrm{x}_{\mathrm{OA}, \min }{ }^{h_{\mathrm{OA}}}+\left(1-\mathrm{x}_{\mathrm{OA}, \min }\right) \mathrm{h}_{\mathrm{RA}}\right]
\end{aligned}
$$

where $\quad x_{H A}=$ the ratio of heating coil air mass flow rate to supply air mass flow rate

$\mathrm{x}_{\mathrm{CA}}=$ the ratio of cooling coil air volumetric flow rate to supply air mass flow rate

$\mathrm{x}_{\mathrm{OA}, \min }=$ the ratio of minimum outdoor air mass flow rate to supply air mass flow rate

Assume that density variation due to temperature differences is negligible, then $\mathrm{x}_{\mathrm{HA}}, \mathrm{x}_{\mathrm{CA}}$, and $\mathrm{x}_{\mathrm{OA}}$, min can be volumetric flow rate ratios instead of mass flow ratios.

Equations (13) and (14) yield:

$$
\begin{aligned}
& q_{\mathrm{H}, \max }^{\prime}=x_{\mathrm{HA}}\left(h_{\mathrm{HA}}-h_{\mathrm{OA}}\right) \\
& q_{\mathrm{C}, \max }^{\prime}=x_{\mathrm{CA}}\left(h_{\mathrm{CA}}-h_{\mathrm{OA}}\right)
\end{aligned}
$$


Defining $B$ as a unit energy cost ratio in terms of dollars of heating to cooling, the dimensionless factor, $\lambda$, can be expressed as:

$$
\lambda=\frac{\left(B q_{H, \min }^{\prime}\right)+\left(-q_{C, \min }^{\prime}\right)}{\left(B q_{H, \max }^{\prime}\right)+\left(-q_{C, \max }^{\prime}\right)}
$$

In equation (19), $\mathrm{q}_{\mathrm{H}, \mathrm{min}}^{\prime}$ and $\mathrm{q}_{\mathrm{H}, \max }$ should be zero or positive, and $\mathrm{q}^{\prime} \mathrm{C}, \mathrm{min}$ and $q^{\prime}{ }_{C}, \max$ should be zero or negative. As a result, $\lambda$ is always positive and can be used as a criteria to decide the outside air damper position. When $\lambda$ is greater than 1 , it is more economical to have the maximum amount of outside air entering the system than the minimum amount of outside air. Therefore, the outside air damper should be opened fully. Otherwise, it should be at its minimum opening position. 
APPENDIX D. COMPUTER PROGRAM LISTING OF THE ENTHALPY ECONOMIZER ALGORITHM WITH ENHANCEMENT (ETC2), AND SAMPLE INPUT AND OUTPUT

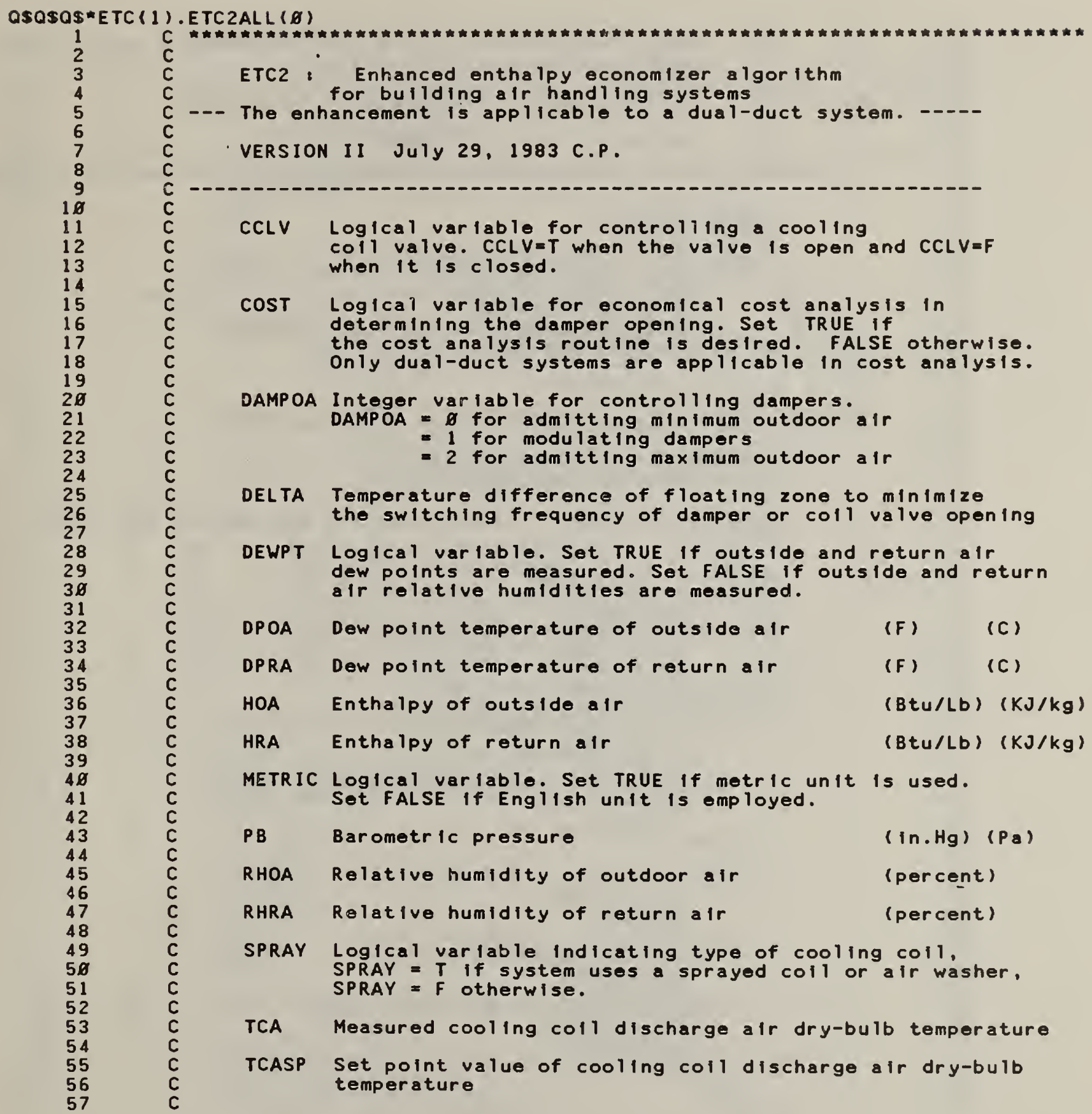




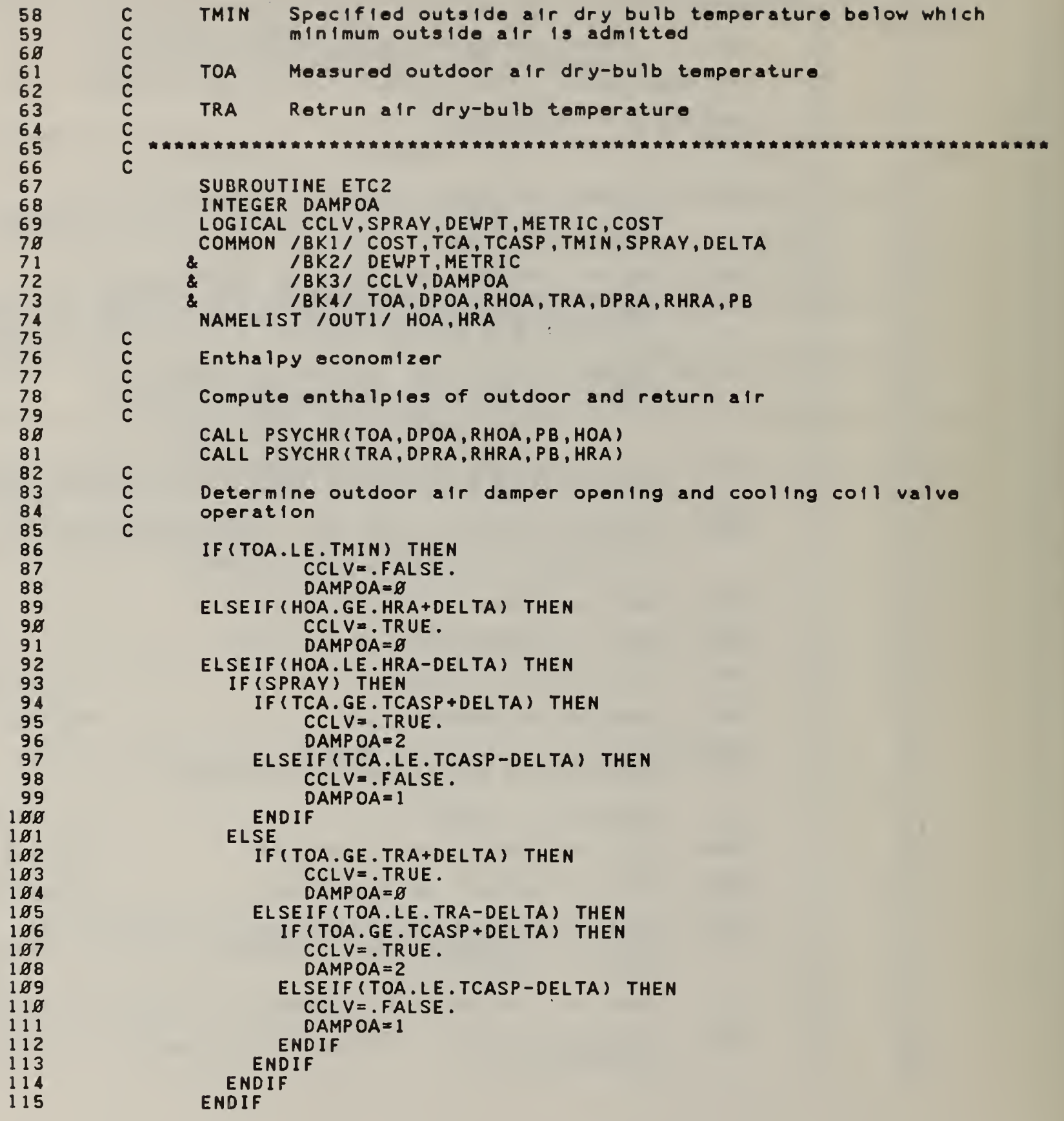




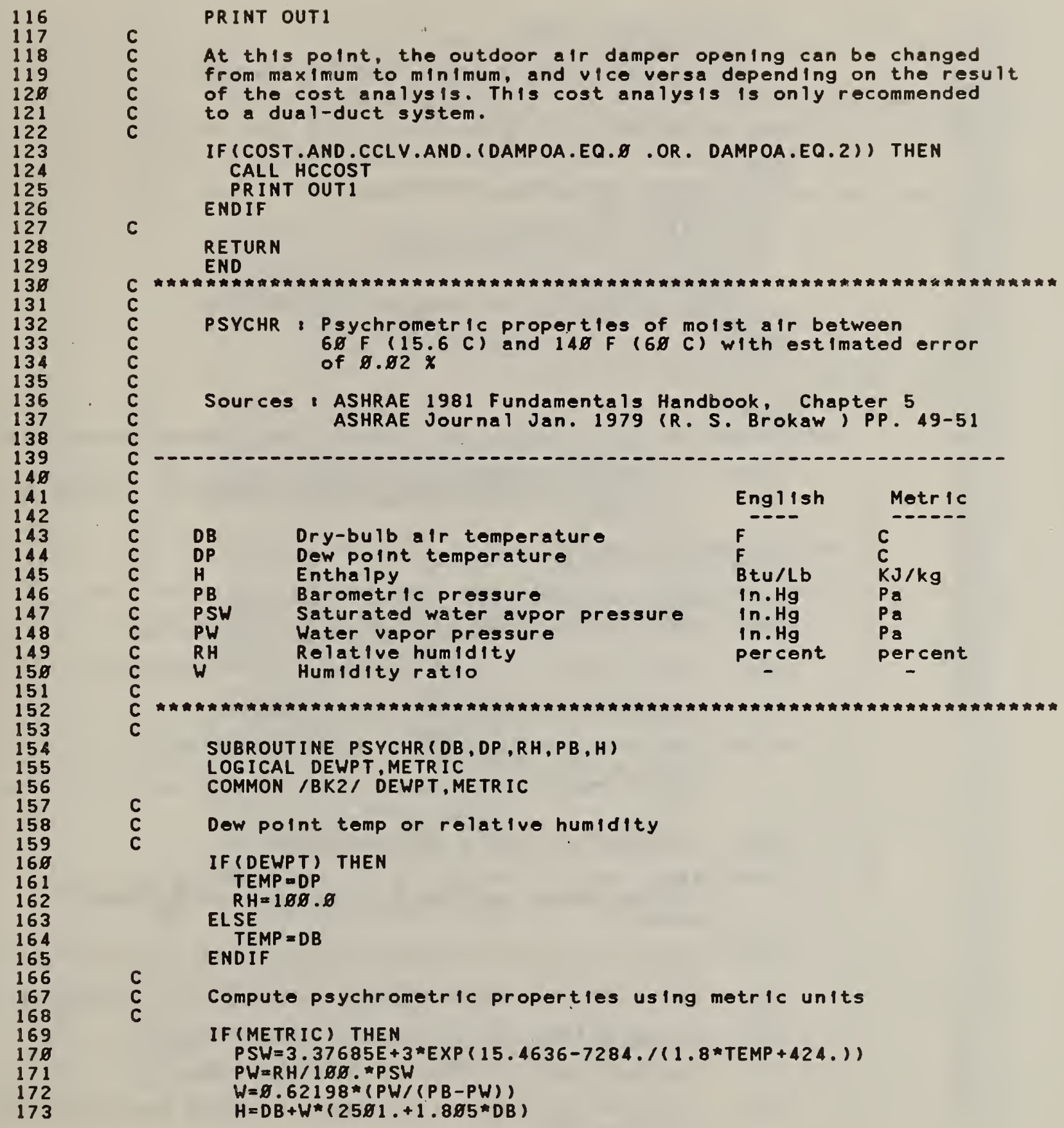



PWLOG=ALOG (PW) ENDIF

$D P=-35.957-1.8726$ *PWLOG+1.1689*PWLOG*PWLOG

Compute psychrometric properties using English units

ELSE

$P S W=\operatorname{EXP}(15.4636-7284 . /(T E M P+392)$.

$P W=R H / 188 . * P S W$

$W=\varnothing .62198$ * $(P W /(P B-P W))$

$H=\varnothing .24 * D B+W *(1861 .+8.444 * D B)$

IF (. NOT.DEWPT) THEN

$P W L O G=A L O G(P W)$

ENDIF

$D P=79.847+38.5798 * P W L O G+1.8893 * P W L O G * P W L O G$

C

ENDIF NDIF

\section{RETURN}

END

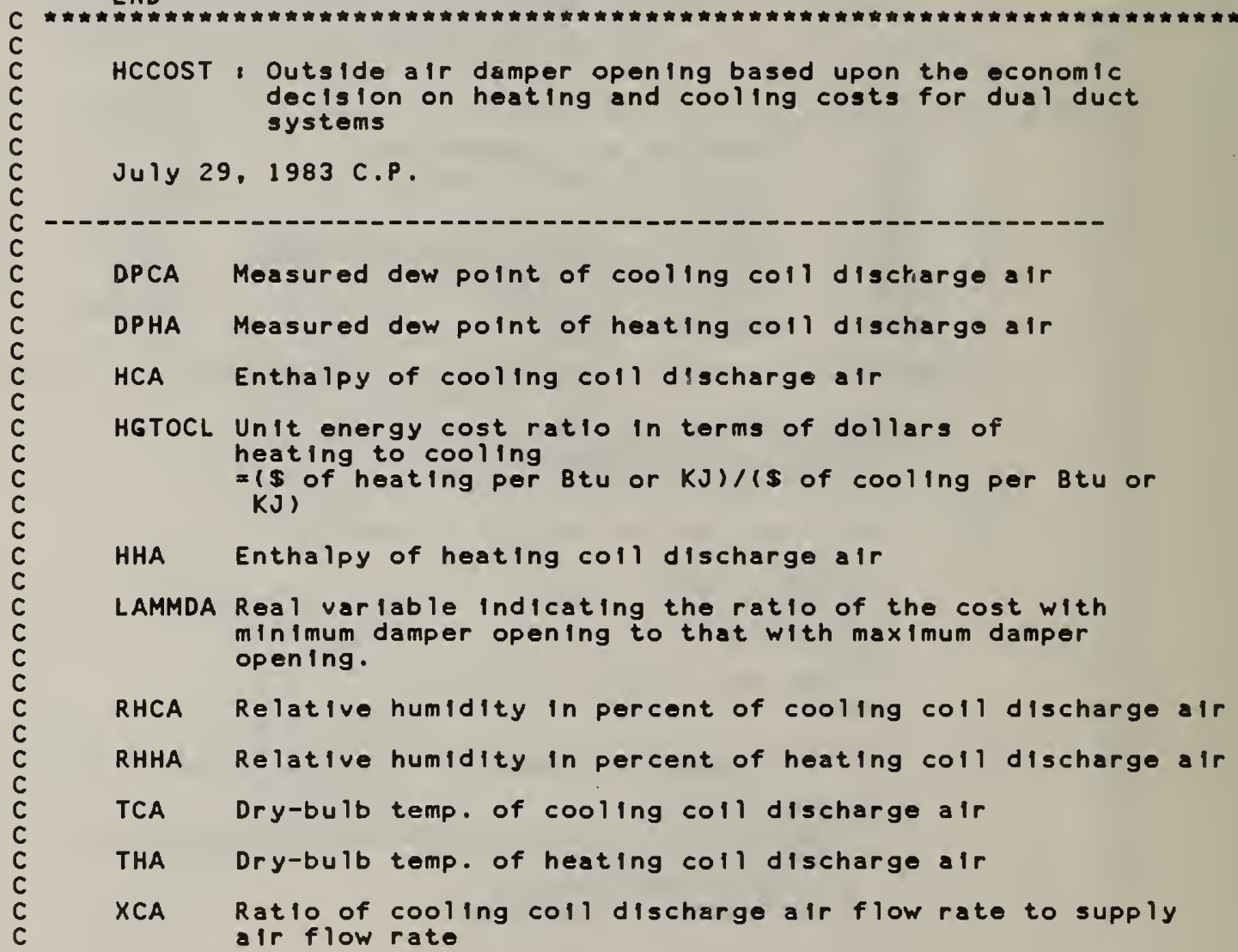




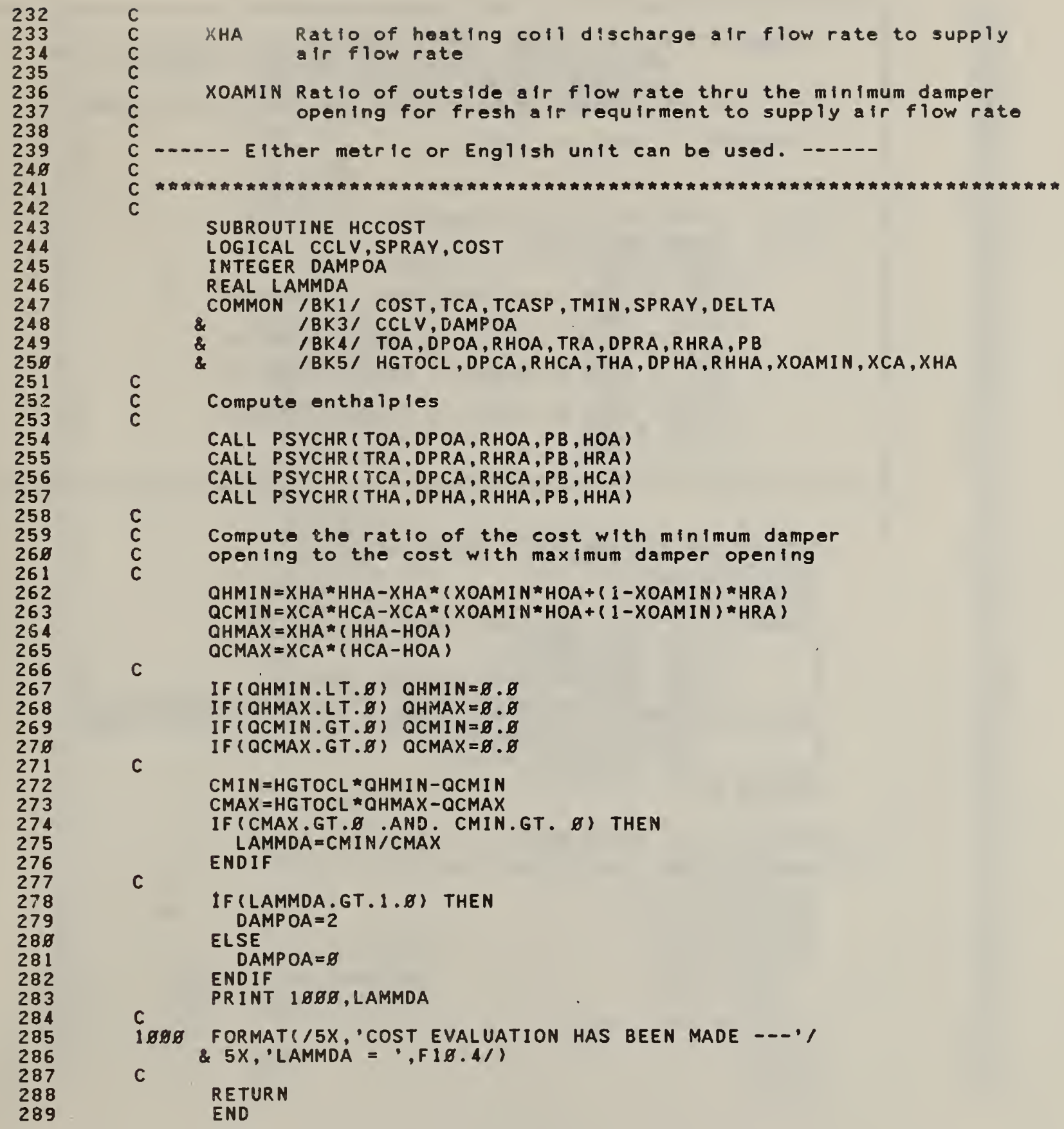




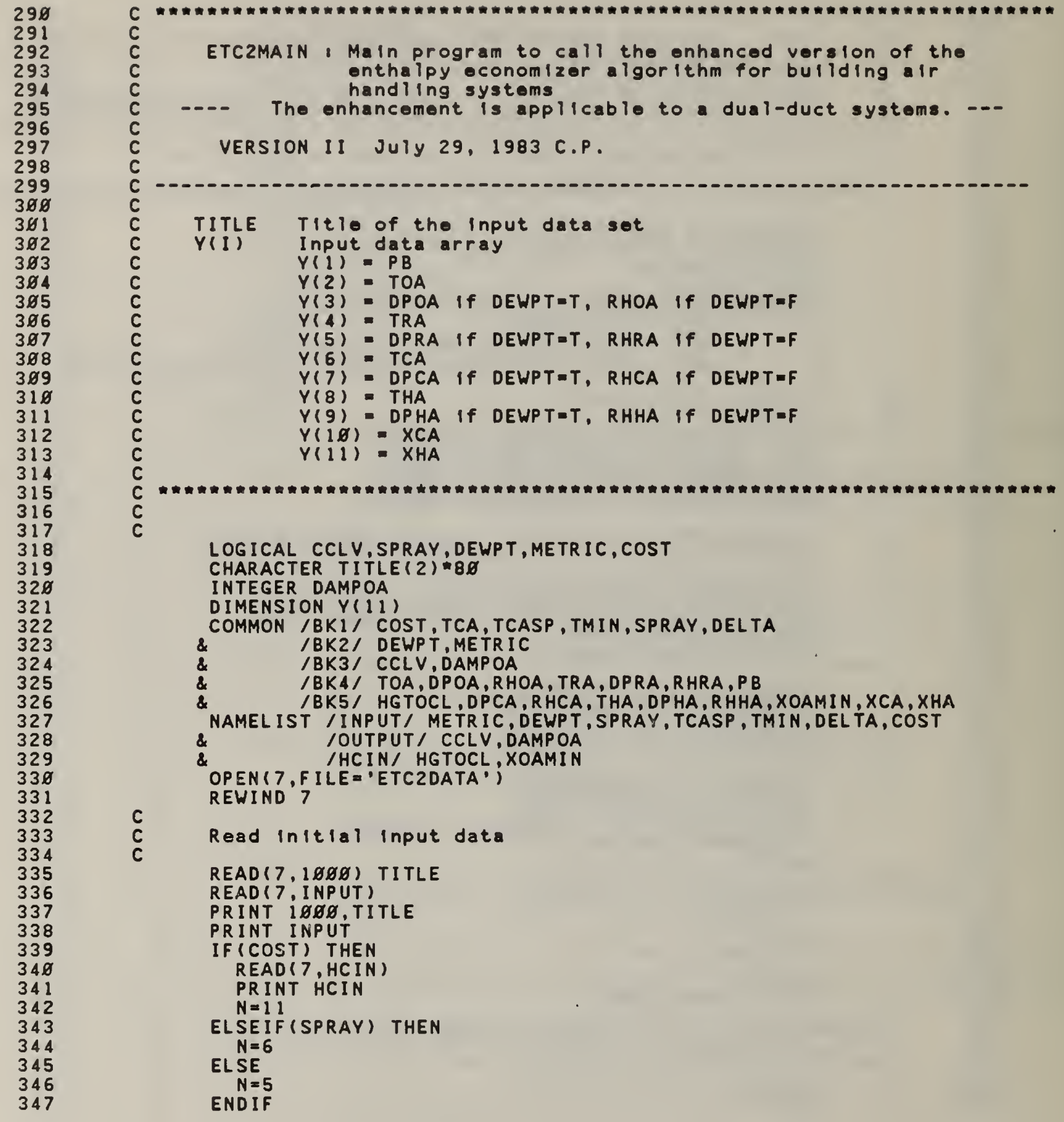




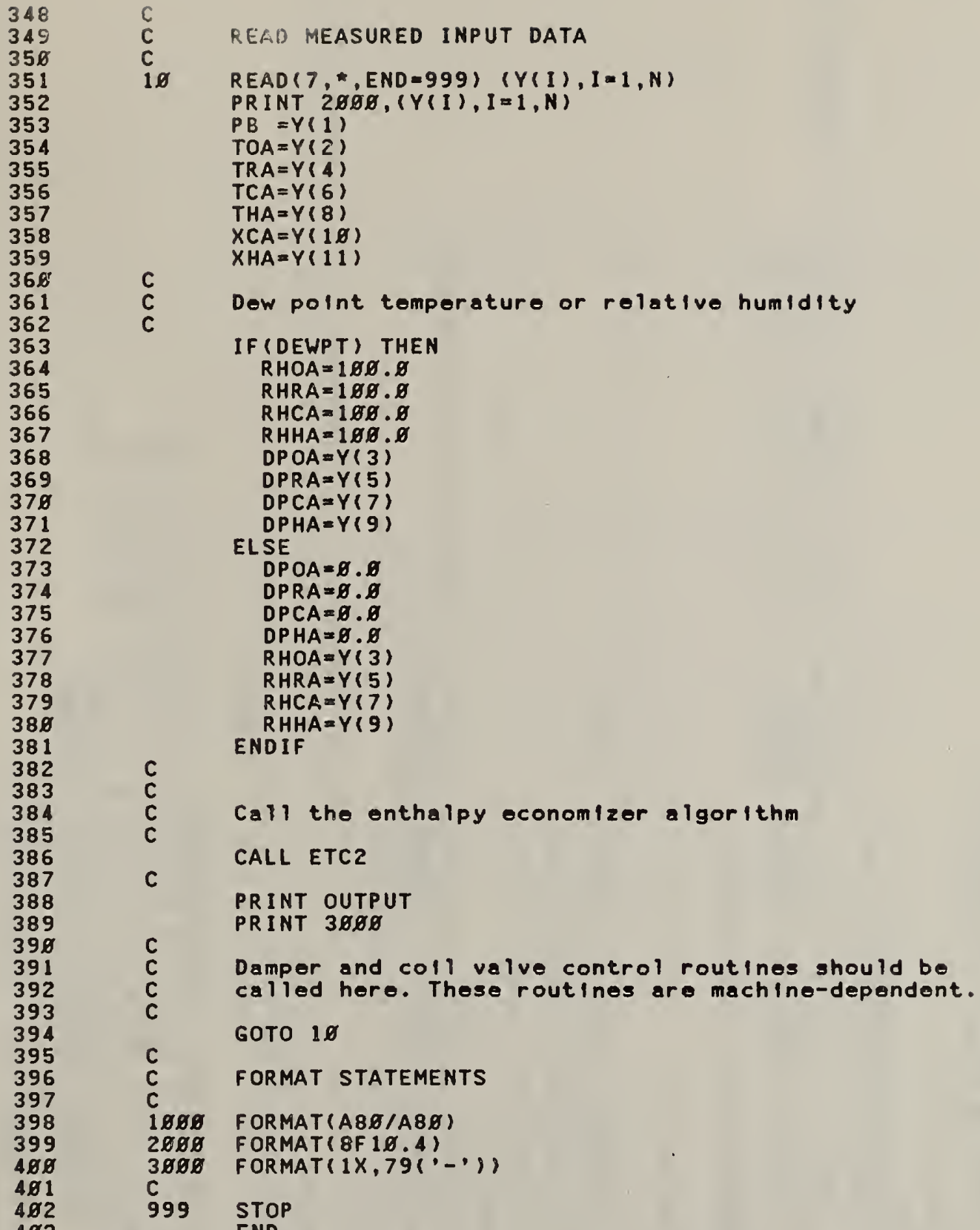

$\mathrm{C}$
$\mathrm{C}$
$\mathrm{C}$

Call the enthalpy economizer algorithm

C

CALL ETC2

PRINT OUTPUT

PRINT 3\%6\%

C Damper and coll valve control routines should bo

C called here. These routines are machine-dependent.

GOTO 10

C FORMAT STATEMENTS

C

1.88\% FORMAT (A8E/A8 8 )

208\% FORMAT (8F10.4)

3.00 FORMAT $\left\{1 \times, 791^{\circ}-1\right)$

C

999 STOP 


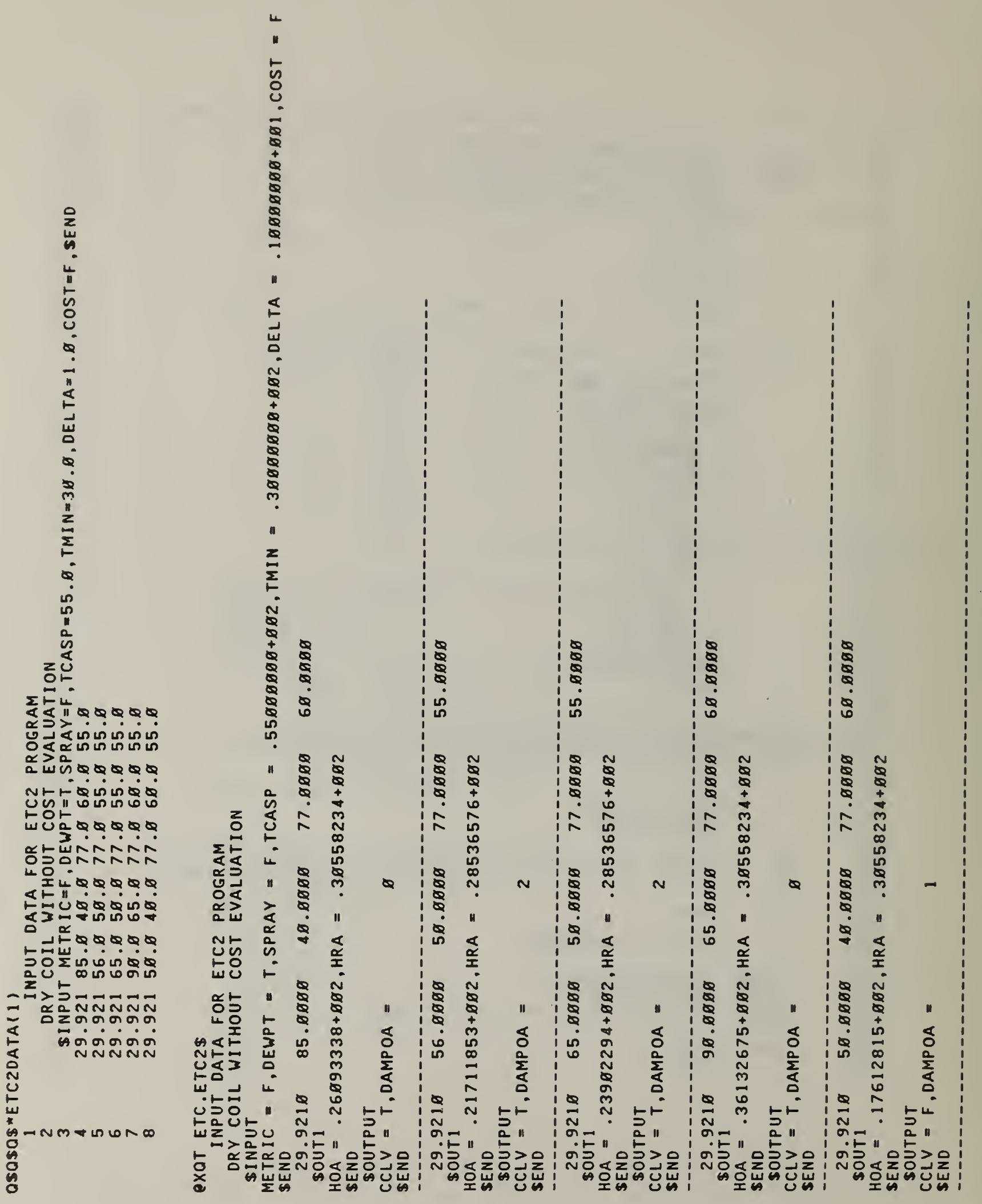




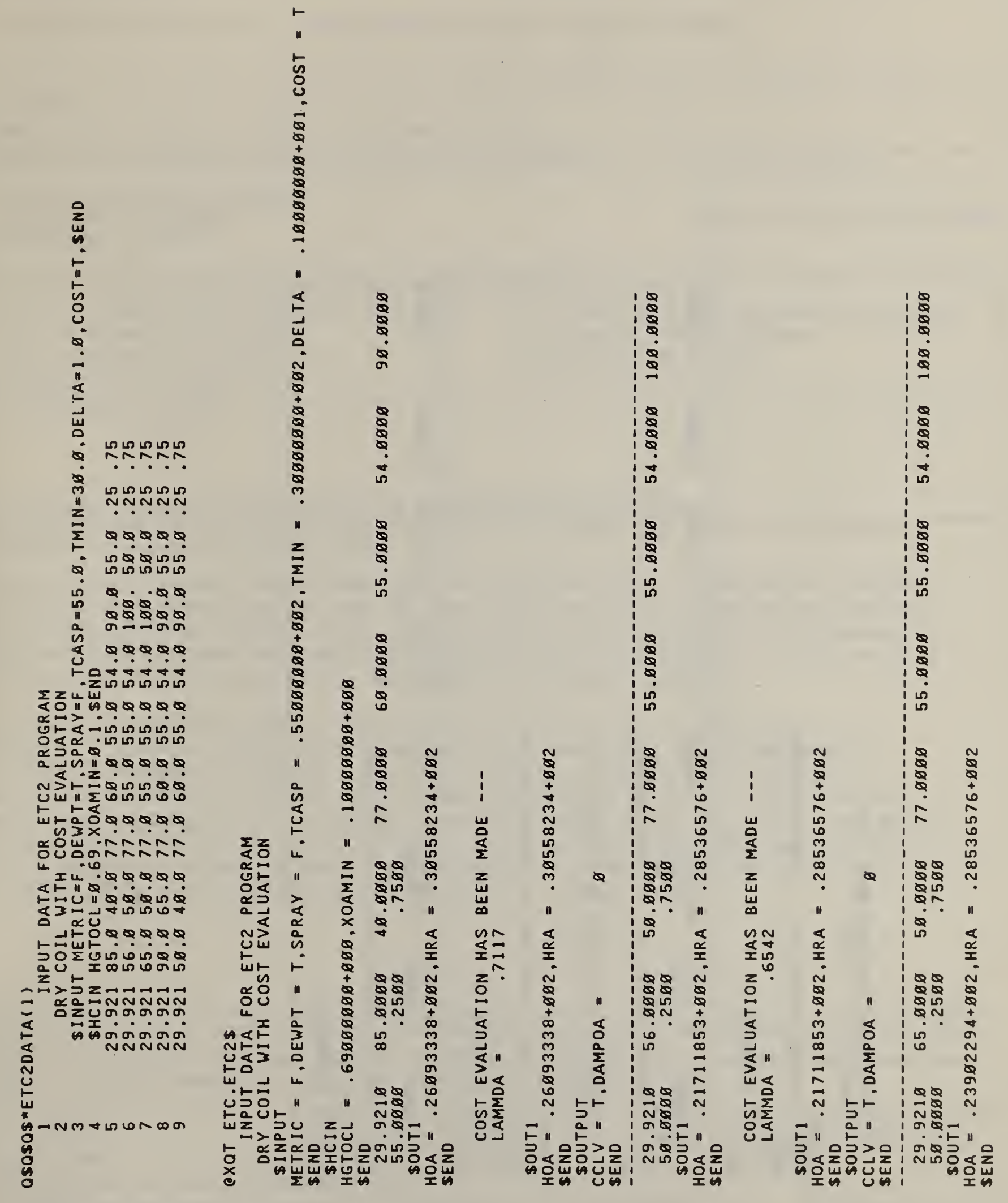




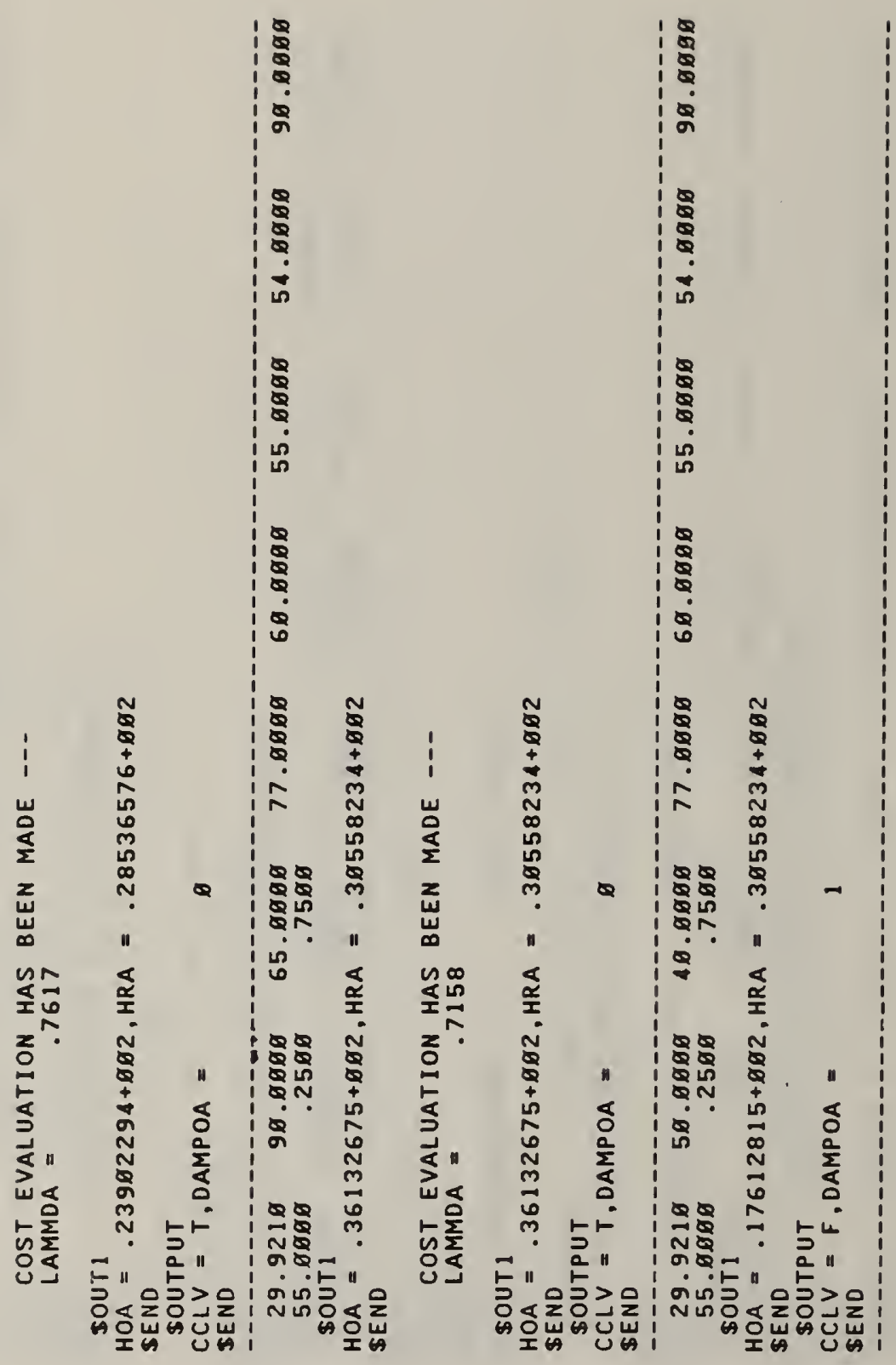


NBS-114A: $\quad$ AQC)

U.S. OEPT. OF COMM.

BIBLIOGRAPHIC DATA

SHEET (cee instructions)

1. PUBLICATION OR REPORT NO.

NBSIR $84-2832$

MARCH 1984

4. TIILE AND SUBTITLE

Economizer Algorithms for Energy Management and Control Systems

5. $A \cup T H O R(S)$

Cheol Park, George E. Kelly, and James Y. Kao

6. PERFORMING ORGANIZATION (If joint or other than NBS, see instructions)

NATIONAL BUREAU OF STANDARDS

DEPARTMENT OF COMMERCE

WASHINGTON, D.C. 20234

9. SPONSORING ORGANIZATION NAME AND COMPLETE ADDRESS (Street. City. State, ZIP)

Office of Buildings \& Community Systems U.S. Navy Civil Engineering Laboratory

U.S. Department of Energy

1000 Independence Avenue, SW

U.S. Department of Defense

Washington, DC 20585

10. SUPPLEMENTARY NOTES

Document describes a computer program; SF-185, FIPS Software Summary, is attached.

11. ABSTRACT (A 200-word or less factual summary of most significant information. If document includes a significant bibliography or literature survey. mention it here)

Economizer cycles have been recognized as important energy conservation measures for building air handling systems and have been included in most Energy Management and Control Systems (EMCS). This report describes the psychrometric processes of the most commonly used economizer cycles and presents algorithms for implementing these cycles on a typical Energy Management and Control System.

Economizer cycles included in this study are dry-bulb and enthalpy types, as applied to both dry coils and sprayed coils. In addition, an enhancement to the normal enthalpy economizer cycle algorithm is presented for dual-duct or multi-zone system which takes into account differences in the costs of heating energy and cooling energy. Computer program listings of the algorithms and sample input/output data are shown in the appendices. A brief discussion of common types of air handling systems is also given to help the reader better understand the application of the algorithms presented in this report.

12. KEY WORDS (Six to twelve entries; alphabetical order; capitallze only proper names; and separate key words by semicolons) control strategies; cooling energy; dry-bulb economizer cycle; energy management and control system; enthalpy economizer cycle; heating energy.

[X Unlimited

$\square$ For Official Distribution. Do Not Release to NTIS

$\square$ Order From Superintendent of Documents, U.S. Government Printing Office, Washington, D.C. 20402.

[X] Order From National Technical Information Service (NTIS), Springfield, VA. 22161

14. NO. OF PRINTED PAGES

81

15. Price 


